\title{
Business Cycles, Unemployment Insurance, and the Calibration of Matching Models ${ }^{a, b}$
}

\author{
James S. Costain \\ Bank of Spain \\ Michael Reiter \\ Universitat Pompeu Fabra \\ First version: June 2003 \\ This version: October 2006
}

\begin{abstract}
This paper theoretically and empirically documents a puzzle that arises when an RBC economy with a job matching function is used to model unemployment. The standard model can generate sufficiently large cyclical fluctuations in unemployment, or a sufficiently small response of unemployment to labor market policies, but it cannot do both. Variable search and separation, finite UI benefit duration, efficiency wages, and capital all fail to resolve this puzzle. However, either sticky wages or match-specific productivity shocks can improve the model's performance by making the firm's flow of surplus more procyclical, which makes hiring more procyclical too.
\end{abstract}

JEL classification: C78, E24, E32, I38, J64

Keywords: Real business cycles, matching function, unemployment insurance

\footnotetext{
${ }^{a}$ Corresponding author: Michael Reiter, Dept. of Economics and Business, Univ. Pompeu Fabra, Ramon Trias Fargas 25-27, 08005 Barcelona, Spain. Phone: +34-93-542-2565. Fax: +34-93-542-1746. Email: michael.reiter@upf.edu.

${ }^{b}$ We gratefully acknowledge research grants from the Spanish Ministry of Education (PB98-1065 and PB98-1066) and Ministry of Science and Technology (SEC2002-01601 and SEJ2004-03619) and from the Bank of Spain. Thanks for data, programs, and comments to Steve Nickell, Andrew Glyn, Wouter den Haan, Monika Merz, Beatriz de Blas Pérez, Christian Haefke, Robert Shimer, Marcel Jansen, Juanjo Dolado, Javier Díaz Giménez, Victor Ríos Rull, Marcus Hagedorn, Juan Francisco Jimeno, and especially to Giulio Fella, John Schmitt, Ernesto Villanueva, and two anonymous referees. We also thank seminar participants at Univ. Pompeu Fabra, the Univ. of Cyprus, FEDEA, Univ. Carlos III, Queen Mary, and the EEA-ESEM 2004 meetings. Errors are the responsibility of the authors.
} 


\section{Introduction}

A model of real business cycles with matching (RBCM) is a natural candidate for exploring many dynamic policy issues. Postulating a job matching function helps us give a coherent analysis of unemployment and its response to labor market policies (see Rogerson, Shimer, and Wright (2005) for a recent survey of matching models). Moreover, Merz (1995), Andolfatto (1996), and den Haan, Ramey, and Watson (2000) have claimed that endogenizing unemployment by means of a matching function improves the fit of real business cycle models. Thus it is tempting to use the RBCM framework to measure the costs of business cycles or the purported benefits of output stabilization, or to ask whether unemployment benefits should vary with the cycle, among other issues.

These questions interest us. But when we tried to build a model to address them, we quickly encountered problems with the RBCM framework which existing literature had not pointed out. For our purposes, we needed a model consistent both with business cycle facts and with the effects of labor market policies. We found it easy to choose parameters to make the cyclical variation in unemployment as large in the model as it is in the data, or to make the response of unemployment to a change in the unemployment insurance (UI) benefit as small in the model as it is in the data. But no calibration permits the standard RBCM model to reproduce both these features: improving the fit over the cycle makes the fit worse with respect to policy, and vice versa. Similar problems occur with employment, vacancies, tightness, and the probability of job finding.

These findings are related to a prominent recent controversy. Shimer (2004, 2005) and Hall (2003, 2005A, 2005B) studied the cyclical dynamics of calibrated RBCM models and obtained fluctuations of unemployment and vacancies an order of magnitude smaller than those in the data. ${ }^{1}$ The reason is that in their models, productivity shocks cause strong wage movements that offset the incentive to vary hiring, thus eliminating most fluctuations in unemployment and vacancies. As a corollary, they also found that a model with sticky wages, instead of the more traditional Nash wage bargaining framework, does a better job of reproducing labor market fluctuations.

While our observations are related to those of Shimer and Hall, we feel that an important element is missing in their argument, because their claim that unemployment is insufficiently variable in the RBCM model is not true in general. In fact, it is specific to their particular calibration: Shimer and Hall both assume that workers' cost of working is low compared to their productivity, so that the match surplus is large. When this restriction is removed, it is easy to make unemployment volatile. If the surplus is small

\footnotetext{
${ }^{1}$ An early paper anticipating Shimer and Hall's results is Millard, Scott, and Sensier (1997).
} 
on average, then a small fall in labor productivity may eat up a large proportion of the surplus, so that realistic productivity fluctuations generate arbitrarily high variability in vacancies, unemployment, and tightness. Stated differently, if the cost of working is acyclical, and is on average only slightly less than after-tax labor productivity, then wages will be relatively rigid and profits and hiring incentives will be strongly procyclical.

The observation that employment is volatile in the RBCM model if the surplus is small has been made again more recently by Hagedorn and Manovskii (2006) in a sharp critique of Shimer and Hall's claims. However, our main point here is that such a calibration only creates another problem. The hiring margin is affected by productivity, taxes, and workers' disutility costs and opportunity costs of labor. If we blow up the impact of productivity by making the surplus small on average, then hiring becomes extremely sensitive to taxes and labor market policies too. We demonstrate analytically in a simple benchmark RBCM model that the responses of unemployment to productivity shocks and to policy variables cannot be simultaneously reconciled with the data. We go on to show numerically that this problem remains when the model is extended in several ways not considered by Shimer and Hall, and is also present but undiagnosed in previous papers.

The recent survey of Hornstein, Krusell, and Violante (2005A) concludes, like us, that solving the unemployment fluctuation problem by making the surplus small is likely to exaggerate the model's policy effects. However, while cyclical labor market dynamics have been extensively documented in recent papers, the policy effects that underlie the other half of our argument are more controversial. Therefore, we also perform a detailed robustness analysis of the best-known cross-country policy regressions. We find that the effects of UI benefits and taxes are quite robustly identified by both cross-sectional and time series evidence, and are approximately equal, as our model implies. Our estimates are somewhat larger than those of Layard and Nickell (1999), and imply that benefits and taxes have economically important effects, but are much too small to be reconciled with the cyclical volatility of unemployment in the standard RBCM model.

Finally, our paper also discusses two possible solutions of our "puzzle". Shimer (2004) and Hall's (2005A,B) argument that sticky wages help by making firms' share of surplus more procyclical also helps resolve our puzzle, as long as wages eventually adjust in the face of long run policy changes. However, we also identify a real mechanism that can reconcile the cyclical and policy-related variation in unemployment. Embodied (that is, match-specific) technological change also increases the cyclicality of the match surplus, especially for the firm, without changing long run policy impacts. While we focus on one particular puzzle for the RBCM model, and propose one new solution, 
several other recent papers make related points. Other empirical criticisms of the RBCM model include Cole and Rogerson (1999), Fujita (2004), and Ravn (2006). Other papers offering ways of improving the model's fit include Mortensen and Nagypal (2006), Silva and Toledo (2005), and Hall and Milgrom (2005).

The next section states our general model. In section 3, we analytically calculate the relationship between the cyclical variability of unemployment and the effects of UI on unemployment in a tractable special case. In section 4, we briefly discuss cyclical stylized facts and then carefully study the robustness of cross-country evidence on policy effects, concluding that these two sets of evidence jointly reject our baseline model. Section 5 shows that neither variable search, variable separation, finite UI benefit duration, nor efficiency wages suffice to make the model fit the data, but that sticky wages or matchspecific productivity shocks might. In section 6 , we discuss some earlier RBCM papers that are not nested in our analysis (mainly because they allow for physical capital), and show that they are subject to the same critique. Section 7 concludes.

\section{The model}

Our general model is a version of the standard RBCM model, as spelled out in Pissarides (2000) and elsewhere. We simplify by ignoring physical capital; including it would be likely to reinforce our "puzzle", since capital can more easily adjust to long term policy changes than to short term business cycle fluctuations. ${ }^{2}$ In hopes of finding a successful version of the model, we generalize in several ways: we allow productivity to vary across matches, and we allow separation rates and bargaining power to vary too.

\subsection{Values and surpluses}

Let $Z$ be a shock to the productivity of the economy, and let $z$ be the value of this shock at the time when a given job was formed. We consider a labor productivity process $y$ that allows the output of a match to depend on its vintage:

$$
y(z, Z)=1+\alpha_{Z} Z+\zeta\left(1-\alpha_{Z}\right) z
$$

In the usual RBC specification $\left(\alpha_{Z}=1\right)$, aggregate productivity fluctuates because technology shocks immediately affect all matches. But alternatively, technological progress

\footnotetext{
${ }^{2}$ See Sec. 6. We also simplify by ignoring two other generalizations that are unlikely to resolve the dilemma at hand. One might want to consider procyclical labor market distortions (since both UI benefits and taxes are typically increasing in the wage) or procyclical hiring costs (since the cost of hiring may consist mostly of labor time). However, these factors would only make firms' hiring expenditure less procyclical, so they are not likely to help resolve the puzzle that concerns us.
} 
could require the creation of new jobs. In that case, productivity would have a matchspecific or cohort-specific component, which would be consistent with Devereux's (2003) evidence that workers tend to find persistently better matches in booms. Setting $\alpha_{Z}=0$ attributes all fluctuations in aggregate productivity to this cohort-specific component. The parameter $\zeta$ allows us to adjust the impact of the match-specific shock $z$ relative to the aggregate shock $Z$.

It is well known that in matching models without a capital stock, surpluses and most decision variables are independent of the unemployment rate. Without mentioning unemployment, we can write transition probabilities in terms of labor market tightness, which in turn depends on productivity. To save on notation, we immediately impose these restrictions by writing the value and policy functions in terms of their appropriate state variables. Later we point out why these restrictions are valid.

If the after-tax wage is $w(z, Z)$, then an employed worker's value, $W^{E}(z, Z)$, is:

$$
W^{E}(z, Z)=w(z, Z)+\beta E_{Z^{\prime} \mid Z}\left[(1-\delta(z, Z)) W^{E}\left(z, Z^{\prime}\right)+\delta(z, Z) W^{U}\left(Z^{\prime}\right)\right]
$$

We generalize to allow the separation rate $\delta$ to depend on productivity. We will see that the probability of finding a job can be written as $p(S, \theta)$, where $S$ is search effort and $\theta$ is labor market tightness. Therefore the value $W^{U}(Z)$ of unemployment is:

$$
W^{U}(Z)=\max _{S}\left\{b-h(S)+\beta E_{Z^{\prime} \mid Z}\left[p(S, \theta(Z)) W^{E}\left(Z^{\prime}, Z^{\prime}\right)+(1-p(S, \theta(Z))) W^{U}\left(Z^{\prime}\right)\right]\right\}
$$

Here $b$ represents the UI benefit, though in general it should also be understood to capture other costs of working, such as disutility costs. $S$ is the intensity of job search and $h(S)$ are the costs of searching. Most of the time we will fix $S=1$ and $h(S)=0$, but we will also investigate the effect of varying search intensity.

The workers' surplus is defined as the difference between the values of employment and unemployment; it satisfies

$$
\begin{aligned}
& \Sigma^{W}(z, Z)=W^{E}(z, Z)-W^{U}(Z) \\
& \quad=w(z, Z)-b+h(S(Z))+\beta E_{Z^{\prime} \mid Z}\left[(1-\delta(z, Z)) \Sigma^{W}\left(z, Z^{\prime}\right)-p(S(Z), \theta(Z)) \Sigma^{W}\left(Z^{\prime}, Z^{\prime}\right)\right]
\end{aligned}
$$

where $S(Z)$ denotes the optimal search at $Z$. If search is endogenous, then it obeys the first-order condition

$$
h^{\prime}(S(Z))=\beta \frac{\partial p(S(Z), \theta(Z))}{\partial S} E_{Z^{\prime} \mid Z^{\Sigma}} \Sigma^{W}\left(Z^{\prime}, Z^{\prime}\right)
$$

The value to the firm of a filled job, $J(z, Z)$, satisfies the recursive equation

$$
J(z, Z)=\Sigma^{F}(z, Z)=y(z, Z)-w(z, Z)-\tau+\beta(1-\delta(z, Z)) E_{Z^{\prime} \mid Z} J\left(z, Z^{\prime}\right)
$$


where $\tau$ represents total labor taxes on the worker and the firm. Unlike a worker's job acceptance decision, filling a job is assumed (as usual) to have no opportunity cost in terms of lost hiring opportunities, so that the surplus $\Sigma^{F}(z, Z)$ associated with a filled job is the same as the value of that job. In other words, firms offer new jobs until the expected profits associated with a vacancy are zero. If the probability of a filling a job is $p^{F}(S, \theta)$, then the zero profits condition is:

$$
\kappa=p^{F}(S(Z), \theta(Z)) E_{Z^{\prime} \mid Z^{\Sigma^{F}}}\left(Z^{\prime}, Z^{\prime}\right)
$$

where $\kappa$ is the flow cost of maintaining a vacancy.

The wage is determined by the Nash bargaining condition

$$
\frac{\Sigma^{W}(z, Z)}{\Sigma^{F}(z, Z)}=\frac{\mu(z, Z)}{1-\mu(z, Z)}
$$

Here we generalize again, by letting bargaining power $\mu$ vary with the aggregate state.

\subsection{The labor market}

We assume that total matches $M$ are given by

$$
M=\gamma V^{1-\lambda} U^{\lambda} S
$$

where $V$ is total vacancies, and $U$ is unemployment. Tightness is defined as $\theta \equiv V / U$ so that it depends on unemployment $U$ rather than effective search $U S$, which is unobservable. Matching probabilities are thus functions of tightness and search:

$$
p(S, \theta)=\frac{M}{U}=\gamma \theta^{1-\lambda} S
$$

and

$$
p^{F}(S, \theta)=\frac{M}{V}=\frac{p(S, \theta)}{\theta}
$$

Equ. (10) implicitly provides a metric for search effort, saying that the individual probability of finding a job is proportional to search.

Note that equations (4), (5), (6), (7), (8), (10), and (11) are seven equations that determine the seven functions $\Sigma^{W}(z, Z), S(Z), \Sigma^{F}(z, Z), \theta(Z), w(z, Z), p(S, \theta)$, and $p^{F}(S, \theta)$, without reference to unemployment $U$. Thus it is reasonable to look for a solution of these equations that is independent of $U$.

As we define the labor market dynamics of our model, we must note that $\alpha_{Z}<1$ implies a distribution of match productivities. To deal with this effect in the simplest possible way, in Section 4 where we allow $\alpha_{Z}<1$ we will assume that productivity 
follows a two-state Markov process, taking a low value $Z^{L O}$ or a high value $Z^{H I}$. We then distinguish between the fraction of the labor force in matches with low productivity, $N_{t}^{L O}$, and the fraction matched with high productivity, $N_{t}^{H I}$. Total employment plus unemployment must sum to one:

$$
N_{t}+U_{t} \equiv N_{t}^{H I}+N_{t}^{L O}+U_{t}=1
$$

If we write total matches at time $t$ as $M_{t} \equiv \gamma \theta\left(Z_{t}\right)^{1-\lambda} S\left(Z_{t}\right) U_{t}$, then the three labor market state variables follow the dynamics

$$
\begin{gathered}
N_{t+1}^{H I}=\left(1-\delta\left(Z^{H I}, Z_{t}\right)\right) N_{t}^{H I}+M_{t} \mathbf{1}\left(Z_{t+1}=Z^{H I}\right) \\
N_{t+1}^{L O}=\left(1-\delta\left(Z^{L O}, Z_{t}\right)\right) N_{t}^{L O}+M_{t} \mathbf{1}\left(Z_{t+1}=Z^{L O}\right) \\
U_{t+1}=\delta\left(Z^{L O}, Z_{t}\right) N_{t}^{L O}+\delta\left(Z^{H I}, Z_{t}\right) N_{t}^{H I}-M_{t}+U_{t}
\end{gathered}
$$

where $\mathbf{1}(x)$ is an indicator function equalling 1 if statement $x$ is true, and 0 if $x$ is false.

Here we see that total job destruction is $D_{t}=\delta\left(Z^{H I}, Z_{t}\right) N_{t}^{H I}+\delta\left(Z^{L O}, Z_{t}\right) N_{t}^{L O}$. Finally, given that there is no capital stock, aggregate output $Q_{t}$ is:

$$
Q_{t}=\left(1-U_{t}\right)\left(1+\alpha_{Z} Z_{t}\right)+\zeta\left(1-\alpha_{Z}\right)\left(N_{t}^{H I} Z^{H I}+N_{t}^{L O} Z^{L O}\right)
$$

\section{Unemployment volatility: cycles and policies}

We now consider the simplest and most standard version of this model, in which productivity is disembodied $(y=1+Z)$, and the separation rate $\delta$ and bargaining power $\mu$ are constant. ${ }^{3}$ For this special case, we can characterize the dynamics explicitly, and calculate how the cyclical variability of labor market aggregates relates to their response to UI policy.

Define total surplus as $\Sigma_{t} \equiv \Sigma_{t}^{F}+\Sigma_{t}^{W}$. Summing equations (4) and (6), and using the fact that the worker's share of surplus is $\mu$, we see that $\Sigma$ must satisfy

$$
\begin{gathered}
\Sigma_{t}=y_{t}-b-\tau+h\left(S_{t}\right)+\beta(1-\delta) E_{t} \Sigma_{t+1}^{F}+\beta\left(1-\delta-p_{t}\right) E_{t} \Sigma_{t+1}^{W} \\
=y_{t}-b-\tau+h\left(S_{t}\right)+\beta\left(1-\delta-\mu p_{t}\right) E_{t} \Sigma_{t+1}
\end{gathered}
$$

where $h(S)=0$ if search is exogenous. We already see that productivity, UI benefits, and labor taxes will affect match surplus in closely related ways, which is the key to our results. In addition, we have the zero profit condition

$$
\kappa=p_{t}^{F} E_{t} J_{t+1}=p_{t}^{F}(1-\mu) E_{t} \Sigma_{t+1}
$$

\footnotetext{
${ }^{3}$ To simplify notation, we now use the time subscript $t$ to denote dependence on the aggregate state $Z_{t}$ (and also on $U_{t}$ where appropriate).
} 
In equations (17) and (18), $p_{t}=\gamma S_{t} \theta_{t}^{1-\lambda}$ and $p_{t}^{F}=\gamma S_{t} \theta_{t}^{-\lambda}$ depend only on tightness $\theta_{t}$ and search effort $S_{t}$. Thus when search is exogenous, (17) and (18) suffice to determine total surplus $\Sigma_{t}$ and tightness $\theta_{t}$.

In the endogenous search case, the first-order condition (5) plus the zero profit condition (18) allow us to eliminate search in favor of tightness:

$$
\frac{\kappa \theta_{t}}{\gamma(1-\mu)}=\frac{h^{\prime}\left(S_{t}\right) S_{t}}{\beta \gamma \mu}
$$

Since $h(S)$ is convex, (18) implies a positive relation $S(\theta)$ between search and tightness: people search harder when jobs are easier to find. We write the elasticity of $S$ as $\eta_{\theta}^{S}(\theta) \equiv\left(1+h^{\prime \prime}(S(\theta)) S(\theta) / h^{\prime}(S(\theta))\right)^{-1}$. In what follows, we will assume that search costs $h(S)$ are small on average, but are sufficiently convex so that job finding responds relatively inelastically to $\theta$. This guarantees existence of a unique equilibrium, and as we will see shortly, large search costs or highly elastic search effort would have counterfactual implications.

\section{Steady state}

In the nonstochastic steady state (indicated by dropping the subscript $t$ ), equations (17) and (18) give two different expressions for $\Sigma$. Substituting for $p$ and $p^{F}$, we have:

$$
\Sigma=\frac{\kappa \theta^{\lambda}}{\gamma S(1-\mu)}=\frac{y-b-\tau+h(S)}{1-\beta\left(1-\delta-\mu \gamma S \theta^{1-\lambda}\right)}
$$

If $S$ is exogenous, then the left-hand side is increasing in $\theta$, and the right-hand side is decreasing in $\theta$, so there exists a unique steady state for $\theta$ and $\Sigma$. In the case of endogenous search, we assume $S$ is sufficiently inelastic so that the same conclusions hold. In particular, we assume the left side of (20) is increasing in $\theta$, which requires:

$$
\lambda^{*} \equiv \lambda-\eta_{\theta}^{S}(\theta)>0
$$

We can use (20) to derive the comparative statics of $\theta$ in terms of UI and taxes. To keep the results unit-free, it will be helpful to do our calculations in terms of the unitless variable $\xi \equiv b / y$, which we will call the "replacement ratio", though more precisely it is the steady state ratio of UI benefits to labor productivity. ${ }^{4}$ Likewise, we will calculate

\footnotetext{
${ }^{4}$ In steady state, the difference between our "replacement ratio" $\xi \equiv b / y$ and the true UI replacement ratio $b / w$ is small; we have verified numerically that the quantitative impact of using $b / y$ instead of $b / w$ is trivial.
} 
the effects of taxes in terms of the unitless variable $\tau / y$, which we call the "tax wedge". Now, let hats represent changes in the log of the steady state. (20) implies:

$$
\lambda \hat{\theta}-\hat{S}=-\frac{b}{y-b-\tau+h(S)} \hat{b}-\left(\frac{\beta \mu p}{1-\beta(1-\delta-\mu p)}\right)[(1-\lambda) \hat{\theta}+\hat{S}]+\frac{h(S)}{y-b-\tau+h(S)} \eta_{S}^{h}(S) \hat{S}
$$

where $\eta_{S}^{h}(S) \equiv h^{\prime}(S) S / h(S)$. We simplify, using (20) again, and writing the equations in terms of $\hat{p}=\left(1-\lambda^{*}\right) \hat{\theta}$. Then the elasticity of the job finding probability with respect to the replacement ratio, $\eta_{\xi}^{p} \equiv \hat{p} / \hat{\xi}=\hat{p} / \hat{b}$, is

$$
\eta_{\xi}^{p}=-\frac{1-\lambda^{*}}{\lambda^{*}}\left(\frac{b}{y-b-\tau+h}\right)\left(\frac{1-\beta+\beta \delta+\beta \mu p}{1-\beta+\beta \delta+\beta \mu p / \lambda^{*}-h \eta_{S}^{h} \eta_{\theta}^{S} /\left(\lambda^{*} \Sigma\right)}\right)<0
$$

The steady state effect of the replacement ratio on unemployment is approximately the opposite of its effect on the job finding probability $p$. In steady state, unemployment satisfies $\delta(1-U)=p U$, which implies

$$
\eta_{\xi}^{U} \equiv \frac{\hat{U}}{\hat{\xi}}=-(1-U) \frac{\hat{p}}{\hat{\xi}}=-(1-U) \eta_{\xi}^{p}>0
$$

Equations (23) and (24) show that $\lambda^{*}>0$ is necessary for UI to affect unemployment positively, as observed in the data; this justifies assumption (21).

\section{Dynamics}

Now consider the dynamics. Suppose that $y_{t}=1+Z_{t}$ is AR1 in logs:

$$
\tilde{y}_{t+1}=\rho \tilde{y}_{t}+\epsilon_{t+1}
$$

where $\epsilon$ is i.i.d. with $E_{t} \epsilon_{t+1}=0$, and $\rho \in(0,1)$. (Now tildes signify log deviations from steady state, and unadorned variables are steady state values or constants.) If we linearize the surplus dynamics (17) and the zero profit condition (18) and impose saddle path stability, we find an explicit formula for the dynamics of the job-finding probability, in terms of the productivity shock:

$$
\frac{\tilde{p_{t}}}{\tilde{y}_{t}}=\frac{1-\lambda^{*}}{\lambda^{*}}\left(\frac{y}{y-b-\tau+h}\right)\left(\frac{1-\beta+\beta \delta+\beta \mu p}{1 / \rho-\beta+\beta \delta+\beta \mu p / \lambda^{*}-h \eta_{S}^{h} \eta_{\theta}^{S} /\left(\lambda^{*} \Sigma\right)}\right)
$$

The close resemblance between (23) and (26) will help us test the model. Intuitively, the model says that a permanent increase in UI or taxes should have exactly the same effect on the surplus process, and therefore on hiring, as a permanent decrease in productivity by the same amount. Since equivalent changes in $b, \tau$, and $y$ mean changes 
by the same absolute amount (instead of equal percentage changes), the clearest way to express our results will be in terms of semielasticities (instead of elasticities). ${ }^{5}$ Writing the semielasticity of job finding with respect to the replacement ratio as $\epsilon_{\xi}^{p} \equiv \eta_{\xi}^{p} / \xi$, we can use (23) and (26) to obtain:

Proposition 1. The dynamic elasticity of the probability of job finding with respect to productivity, and the long-run semielasticity of the probability of job finding with respect to the replacement ratio $\xi$, have the following ratio in absolute value:

$$
\left|\frac{\tilde{p}_{t} / \tilde{y}_{t}}{\epsilon_{\xi}^{p}}\right|=\left(\frac{1-\beta+\beta \delta+\beta \mu p / \lambda^{*}-h \eta_{S}^{h} \eta_{\theta}^{S} /\left(\lambda^{*} \Sigma\right)}{1 / \rho-\beta+\beta \delta+\beta \mu p / \lambda^{*}-h \eta_{S}^{h} \eta_{\theta}^{S} /\left(\lambda^{*} \Sigma\right)}\right) \leq 1
$$

This ratio equals one if and only if $\rho=1$, and is strictly less than one if $\rho<1$. That is, a permanent increase in labor productivity has the same effect on hiring as a permanent decrease in UI benefits by the same absolute amount, while a temporary rise in labor productivity would have a smaller impact. Endogenous search leaves this ratio unchanged if $\rho=1$, and makes it smaller if $\rho<1$, because the search term $h \eta_{S}^{h} \eta_{\theta}^{S} /\left(\lambda^{*} \Sigma\right)$ decreases the numerator proportionally more than the denominator. Also, it is easy to verify that exactly the same formula can be derived if we replace $\eta_{\xi}^{p}$ by the semielasticity of job finding with respect to the tax wedge.

For comparison with the data it is helpful to translate Prop. 1 into a statement about unemployment. Turning to the dynamics of $U$, we have:

$$
U_{t+1}=U_{t}+\delta\left(1-U_{t}\right)-\gamma S_{t} \theta_{t}^{1-\lambda} U_{t}
$$

In the appendix we calculate the ratio of the standard deviations of the logs (the usual business cycle volatility measure) of unemployment and the technology shock, which we can then compare to the semielasticity $\epsilon_{\xi}^{U} \equiv \partial \log U / \partial \xi$ of unemployment with respect to the replacement ratio. Using the notation $\sigma_{x} \equiv \sqrt{\operatorname{Var}\left(\tilde{x}_{t}\right)}$, we obtain:

Proposition 2. The relative standard deviation of log unemployment to log output, and the long-run semielasticity of unemployment with respect to the replacement ratio $\xi$, have the following ratio:

$$
\frac{\sigma_{U} / \sigma_{Q}}{\epsilon_{\xi}^{U}}=\frac{\left(\sigma_{y} / \sigma_{Q}\right)\left(\sigma_{U} / \sigma_{y}\right)}{\epsilon_{\xi}^{U}}=\left|\frac{\tilde{p}_{t} / \tilde{y}_{t}}{\epsilon_{\xi}^{p}}\right|\left(\frac{\delta(U+\rho(U-\delta))}{(2 U-\delta)(U+\rho(\delta-U))}\right)^{\frac{1}{2}} \frac{\sigma_{y}}{\sigma_{Q}}
$$

\footnotetext{
${ }^{5}$ Another crucial reason to state our results in terms of semielasticities is that our model's $b$ should actually be interpreted as the sum of the UI benefit (observed) and the disutility of working (unobserved). The semielasticity of unemployment with respect to the total cost of working $b$ is the same as the semielasticity with respect to observed UI benefits. In contrast, the elasticity with respect to $b$ cannot be directly estimated without assumptions about the size of the unobserved disutility component.
} 
The left side of Prop. 2 is easily observable. The relative volatility $\sigma_{U} / \sigma_{Q}$ can be calculated from standard macroeconomic data; and following Layard and Nickell (1999), we will regress log unemployment on the replacement ratio across countries to estimate $\epsilon_{\xi}^{U}$. On the right side, the first term is strictly less than one unless technology shocks are permanent. The second term is less than or equal to one if $U>\delta$, which is true if and only if $\delta+p<1$. Thus this restriction is satisfied unless we choose an inappropriately long period (a Cobb-Douglas matching model like this is not well behaved if periods are so long that transition probabilities are near one). The last term is less than one in the data, and it cannot exceed one in our model except in the irrelevant case of a large positive correlation between $y$ and $U$. Thus for any sensible parameters, all three terms on the right hand side are weakly less than one, strictly so in the case of the last term. ${ }^{6}$

\section{Empirical evidence}

We have shown that the RBCM framework implies a tight relationship between cyclical and policy-related variation in unemployment and other labor market variables. Next, we briefly discuss labor market fluctuations (which have been extensively reviewed elsewhere recently), and then explore the effects of labor market policies in greater detail.

\subsection{Unemployment over the business cycle}

For evidence on cyclical fluctuations, we consider US data from 1951:1 to 2006:2 from the St. Louis Fed's FRED database, either using quarterly series, or monthly series aggregated to quarterly frequency. We use series GDPC1 for our measure of real output, UNEMPLOY for the number of unemployed workers, the advertising index HELPWANT for vacancies, and UEMPMED for median unemployment duration. All series discussed below are seasonally adjusted, logged, and detrended with the HP filter, unless otherwise specified. Following Shimer (2005), we set the HP smoothing parameter to 100000 , because otherwise the implied HP unemployment trend comoves strongly with the NBER-identified business cycle. Thus, let $\sigma_{X}$ denote the standard deviation of the HP cyclical component of the log of variable $X$. In our sample, the volatility of $\log$ GDP, $Q$, is $\sigma_{Q}=0.0252$. By contrast, $\log$ unemployment $U$ fluctuates almost

\footnotetext{
${ }^{6}$ We should emphasize that this result is independent of the mean unemployment rate $U$. In the numerator, $\sigma_{U}$ is approximately the standard deviation of unemployment divided by $U$. In the denominator, $\epsilon_{\xi}^{U} \approx U^{-1} \partial U / \partial \xi$. So $U^{-1}$ cancels, meaning our results do not depend on how we calibrate mean $U$, and also do not depend on using logs rather than levels of $U$.
} 
eight times as much: $\sigma_{U}=0.1933$, giving the ratio $\sigma_{U} / \sigma_{Q}=7.66 .{ }^{7}$ Similarly, the log of the median unemployment spell duration has a standard deviation of 0.1732 after HP filtering. Vacancies $V$ are also highly volatile: $\sigma_{V}=0.1974$.

Another striking labor market fact is the robust negative correlation between the cyclical components of log unemployment and log vacancies, -0.884 in our data. Given this correlation, the tightness ratio $\theta=V / U$ is even more volatile than the two series separately: $\sigma_{\theta}=0.3736$. By contrast, employment $N$, wages $w$, and labor productivity $y$ are even smoother than GDP: $\sigma_{N}=0.0137, \sigma_{w}=0.0140$, and $\sigma_{y}=0.0164$ using FRED series CE16OV, COMPRNFB, and OPHNFB.

The key point here is the high volatility of unemployment (and vacancies and tightness) relative to its own mean. ${ }^{8}$ This robust finding has been discussed in many other studies; see for example Merz (1995), Cole and Rogerson (1999), and Greenwood, Gomes, and Rebelo (2001) for similar second moments. Shimer (2005) reports that workers' job finding probability $p$ is also volatile, with $\sigma_{p}=0.118$.

\subsection{Literature on labor market policy and unemployment}

Our paper's implications for labor market policy effects are general equilibrium predictions, like its implications for business cycles. To test these predictions we need to see whether different labor market policies lead to aggregate changes in unemployment and vacancies. One way to do this is to use time series data on the effects of policy in a single country. Since large policy changes are relatively rare, this strategy typically involves case studies of major reforms that act as "natural experiments". 9 Unfortunately, such studies are few and far between, and their reliance on unique events makes them hard to interpret. Another possibility which might seem useful would be to study microeconomic data on how different policy treatments affect individual labor market outcomes. Studies of this sort are plentiful but are not directly relevant since they only identify the partial equilibrium effect of policy on workers' choices. Layard, Nickell, and Jackman's (1991) survey argues that the consensus range of estimates for the elasticity

\footnotetext{
${ }^{7}$ Setting the HP smoothing parameter to 1600 only strengthens our results, raising $\sigma_{U} / \sigma_{Q}$ to 7.87 , because lowering the parameter decreases $\sigma_{Q}$ more than $\sigma_{U}$.

${ }^{8}$ It is quantitatively unimportant whether we make this point in terms of the log of the number unemployed, the log of the unemployment rate, or the mean and standard deviation of the unemployment rate. Studying the $\log$ or the coefficient of variation of unemployment might seem strange to those accustomed to frictionless models where unemployment is just a residual. But the log-linear matching technology in the RBCM framework places strong restrictions on the fluctuation of unemployment, relative to its mean, which are central to calibrating the model.
}

${ }^{9}$ See for example Solon (1985), Hunt (1995), and Bennmarker, Carling, and Holmlund (2005). 
of unemployment duration with respect to UI benefits is 0.2 to 0.9 ; this is only relevant for us insofar as it is smaller than the general equilibrium estimates we discuss below.

Thus, by process of elimination, we believe that the best evidence on these issues comes from international cross-sectional or panel-data studies. Adequate data for this purpose have been compiled by the OECD for many of its member countries, often going back to 1960. Layard et. al. (1991) used these data to calculate the impact of unemployment benefits and other labor market policy variables; they have updated their estimates with expanded data several times. For purposes of comparison, we will take as our benchmark the methodology and estimates of Layard and Nickell (1999, henceforth LN99), who find that the semielasticity of unemployment with respect to the UI benefit replacement ratio is 1.3 , with a standard error of 0.5. ${ }^{10}$ Similar results, for related data sets, are reported by Scarpetta (1996) and Disney (2000). While some studies have argued that the effects of UI are smaller (Baker et. al. (2003) claim that the UI effects in OECD data are not significant), the largest cross-country estimates of UI effects we know of are not much bigger than those of LN99.

Some recent studies are more ambitious, addressing higher-frequency data and attempting to identify interaction terms. Blanchard and Wolfers (2000) study how institutions interact with shocks; Belot and van Ours (2004) interact different institutions; Nickell, Nunziata, and Ochel (2005) use annual data to identify both institutional interactions and country-specific trends. Baker et. al. (2003, 2004) provide an excellent overview and critique of these and other recent studies (Elmeskov et. al. 1998; Fitoussi et. al. 2000; Bertola et. al. 2001). While these papers' estimates vary widely, the important point for our purposes is that none of them find substantially larger effects of unemployment benefits than those we estimate. ${ }^{11}$

\subsection{Possible problems with cross-country estimates}

Cross-country regressions to measure the impact of policy are frequently criticized, ${ }^{12}$ and concern is justifiable on at least three grounds. First, the number of countries and periods is inevitably rather small, and data on institutions and policy variables may

\footnotetext{
${ }^{10}$ LN99 regress log unemployment on the replacement rate and other labor market policies and controls for 20 OECD countries. They run GLS in order to allow for random country effects, treating 1983-88 and 1989-94 averages as separate observations, and including a time dummy for 1989-94.

${ }^{11}$ The largest estimate obtained in these papers is that of Elmeskov et. al. (1998), who find that a 10 percentage point rise in the replacement ratio would raise unemployment by 1.29 percentage points. See the summary table on p. 36 of Baker et. al. (2003).

${ }^{12}$ E.g. Levine and Renelt (1992) and Durlauf and Quah (1999) in the growth literature. Hagedorn and Manovskii (2006) reject out of hand the use of cross-country data to evaluate policy effects.
} 
be of poor quality. More precisely, since each country has its own statistical agency, data definitions may differ, and variables may be missing for some countries or periods. A second, related point is that a fully structural estimate of the impact of policy and institutions would probably require additional variables on which no data exist at all. Therefore, cross-country studies estimate reduced form relationships, leaving reasonable doubts about robustness to econometric variations. Third, results may be biased due to endogeneity problems. Rather than identifying the effects of policy on unemployment, regressions could capture reverse causation from unemployment to changes in policy. The purpose of our empirical work is to investigate how the results of LN99 and related papers hold up in the face of these three lines of criticism.

The issues of data inconsistency between countries, and possibly omitted time series or cross-sectional regressors, make it essential to check how results change when we control for time effects and country effects. For institutional variables such as unemployment benefits and labor tax wedges, changes over time within a country are probably better measured than differences across countries. If we find similar results along the time series dimension and along the cross-sectional dimension, this suggests that it is not just poor data quality which drives the results. Moreover, given our robustness concerns, we control for country and time effects in several ways: we try fixed effects, random effects, and cluster corrections for the cross-sectional dimension, and both fixed effects and macroeconomic control variables in the time dimension.

Many further aspects of our estimation strategy help mitigate our remaining concerns. We use a much longer time sample than LN99, and we compare regressions for two different data sets. We also run a wide variety of specifications, studying different sample periods, exclusion of possible outliers, and the exclusion of different combinations of regressors. Also, we exploit the fact that in our model, the coefficient of interest can be estimated from taxes, or from benefits, or from their sum. As for the endogeneity problem, the main concern is that countries with persistently high unemployment could be forced, for budgetary reasons, to lower benefits and raise taxes. We check for endogeneity by regressing unemployment on lagged policies instead of contemporaneous policies. Moreover, since budgetary pressures tend to push benefits and taxes in opposite directions, the coefficient on their sum $\tau+b$ is less likely to suffer endogeneity bias than those on taxes and benefits separately. This is another good reason to focus on the sum. We find no evidence that endogeneity biasses our results, and our main findings turn out to be distinctly robust. Especially when we look at the total labor supply distortion $\tau+b$, we repeatedly obtain a semi-elasticity of about 2 . 


\subsection{Impact of benefits and taxes on unemployment}

We now run a variety of cross-country regressions to estimate the effect of the UI replacement ratio and the tax rate on log unemployment. We base our regressions on those of Layard and Nickell (1999). Like them, we try to avoid complex time series methods by aggregating the data to a lower frequency: we average all variables over five year periods before estimation. But we extend their results in several ways. First, by studying a long sample, from 1960 to 1999, we show that the cross-sectional and the time series variation in our data both provide similar evidence on policy effects. Second, we run many robustness checks, especially in relation to the sample period and possible outliers. Third, we test and then impose our model's restriction that the coefficients on taxes and benefits should be equal, thus improving the stability of our estimates.

We use two data sources: the Labor Market Institutions Database of Nickell and Nunziata (2001), and an expansion of this dataset, extended to 1999 and including more series, constructed by the IMF and by Baker et. al., (2003). Except where otherwise noted, the results are based on the latter. The dependent variable is the log of the five-year average of the unemployment rate. The regressors include either the tax wedge and the UI benefit replacement ratio separately, or the sum of the two. We usually also include indices of benefit duration, employment protection, union density, and bargaining coordination, and the percent of households who are owner-occupiers. However, the coefficients of interest are those on benefits and taxes, since our propositions show that these bear a direct relation to the effects of productivity shocks. Some regressions also include an active labor market policy index (ALMP), or the cross-country mean of the output gap. Data sources and definitions are described in Appendix 2, which also provides the address of a web page where our data can be downloaded.

Our benchmark estimates are reported in Table 1. When possible, we use the same variables as LN99, scaling them all (except benefit duration, which is defined differently in LN99) to make our coefficients directly comparable to those reported in their Table 15. The first two columns show OLS estimates without country or time dummies, but with robust standard errors based on a cluster correction by country; the estimated coefficients on the tax wedge (semielasticity 4.21) and UI benefits (semielasticity 1.70) are both moderately larger than those reported in LN99. The remaining columns control for country effects or time effects in a variety of ways; column 7 shows the LN99 specification, which is a GLS regression with random country effects and fixed time effects. As in LN99, bargaining coordination has a negative effect on unemployment, sometimes significant; and the percentage of households which are owner occupiers has a significant positive effect on unemployment, which makes sense if countries with more 
rental housing attain greater labor market flexibility. One notable difference between our benchmark estimates and LN99 is that we do not find significant effects of benefit duration, employment protection, or union density.

As we mentioned in Sec. 3, our matching framework implies that the semielasticities of unemployment with respect to the tax wedge and the UI benefit should be roughly equal. When we test this prediction in our data, we find a significant difference (at the $5 \%$ level) between the coefficients on taxes and benefits in only one of the five specifications considered in Table 1. Therefore it is also interesting to impose the restriction that the coefficients are equal, by regressing on the sum of the tax wedge and the replacement ratio. When we do so (even-numbered columns of Table 1), we obtain a notably more stable coefficient: the estimated semielasticity with respect to the sum $\tau+b$ ranges from 1.33 (running GLS with random country effects and fixed time effects) to 2.45 (without controls for country or time effects). Four of the five coefficients are significant at $1 \%$, and all of them at $10 \%$. Thus these estimates strongly suggest that the semielasticity that interests us is approximately two.

Regressing on taxes and benefits separately while controlling both for unobserved country-specific and time-specific factors requires us to estimate a large number of coefficients relative to the modest amount of data available. This implies less stable results, as in column 7 of Table 1, where the tax coefficient falls to zero. Nonetheless, our reading of Table 1 and also Table 2, which reports the coefficient on $\tau+b$ for many alternative specifications, is that there is strong cross-sectional and time series evidence for a semielasticity of approximately two. Moderately larger effects are found in the country effects regressions ${ }^{13}$ (i.e. in within-country time series variation in the data) than in the time effects regressions ${ }^{14}$, but the coefficients are similar. Moreover, when we take advantage of the greater stability implied by regressing on the sum $\tau+b$, we obtain a robustly significant semielasticity, around 1.5, even if we allow for time effects and country effects simultaneously (columns 5 and 8 of Table 2). Finally, we also try to economize on coefficients by regressing on the cross-country mean of the output gap instead of including time dummies. ${ }^{15}$ As expected, the coefficient on the output gap is negative and usually highly significant; taxes, benefits, and taxes plus benefits all tend

\footnotetext{
${ }^{13}$ Columns 5 and 6 of Table 1 and columns 4 and 7 of Table 2. We never find systematic differences between fixed and random effects.

${ }^{14}$ Columns 3 and 4 of Table 1 and column 2 of Table 2; standard errors are cluster-corrected across countries in these regressions.

${ }^{15}$ The tables report results using the unweighted cross-country mean of the output gap. If we instead use a weighted mean, with weights corresponding to the size of the labor force, results are similar.
} 
to have robust, significant coefficients, around two, in specifications where the mean output gap is used instead of time effects.

Table 2 considers many additional robustness issues. The regressors are the same ones listed in Table 1, unless otherwise stated, but only the coefficient on taxes plus benefits is shown. First, we try eliminating the pre-1975 data, which may be less reliable. The coefficient on $\tau+b$ decreases somewhat; the most interesting effect (not in the table) is that benefit duration usually has a significant positive coefficient in post-1975 estimates. Splitting the sample at 1980 or 1985 yields similar results; the coefficient on $\tau+b$ is larger but less significant in the early subsample, and smaller in the later subsample, where much of the impact of benefits is instead picked up by duration. In row 3, we replace the BGHS data (available to 1999) with the LMIDB dataset (available to 1995); the coefficient on $\tau+b$ decreases moderately unless both time and country dummies are included, which makes it insignificant. Next, we try excluding Scandinavia, where unemployment rates have remained generally low in spite of large benefit increases over our sample period, perhaps due to generous spending on reemployment and retraining policies. A nontrivial increase in the coefficient on $\tau+b$ is observed, to around 3.5. As an alternative control for this type of social spending, row 5 reports regressions that include an indicator of spending on "active labor market policies" (ALMP); this series is limited to 1985-99 and requires an instrumental variables treatment, as in LN99. The coefficient falls to around 1.5 (but is higher than in a 1980-95 regression without ALMP). In the last two rows of results, we check how the other regressors affect the coefficient on $\tau+b$. Eliminating employment protection, union density, and benefit duration, which are insignificant in the full 1960-99 sample, has little effect on the estimates; eliminating bargaining coordination and the owner occupancy rate (which are usually significant) tends to decrease the coefficient and its significance.

The possible endogeneity of policy is addressed in Table 2, row 6, and also in Table 3 , where we regress unemployment on lagged policies. ${ }^{16}$ The issue is that high unemployment could worsen the government's finances and force it to raise taxes (or lower benefits), biassing down the coefficient on taxes (and biassing up that on benefits). The effects of taxes and benefits appear slightly more stable in Table 3, with lagged policies, than in the otherwise identical regressions of Table 1. In fact, the insignificant negative tax effect found in column 7 of Table 1 might be due to endogeneity; this coefficient becomes positive and significant in Table 3. Nonetheless, comparing Tables 1 and 3 shows that including lagged rather than current policy can either increase or decrease

\footnotetext{
${ }^{16}$ That is, we regress the log of the mean of the unemployment rate from $t$ to $t+4$ on the mean of each policy variable from $t-1$ to $t-5$.
} 
the coefficient on taxes, and likewise that on benefits, so the evidence for endogeneity is weak. Also, as we mentioned earlier, an endogeneity problem is less likely when we regress on the sum $\tau+b$ instead of on taxes and benefits separately. Comparing the third rows of Tables 1 and 3, or rows 1 and 6 of Table 2, we find that the coefficient on $\tau+b$ is virtually unchanged by using lagged rather than current policy.

In summary, our estimate of the semielasticity of unemployment with respect to benefits is somewhat larger than LN99 found: two instead of 1.3. Our higher estimate probably results partly from the effect of taxes, which tend to have an (insignificantly) higher coefficient than UI benefits when the two are treated separately. Also, LN99 used data from 1984 onwards, and in this period an important part of the impact on unemployment is attributed to benefit duration rather than to benefit levels per se. Third, LN99 ran a GLS regression with random country effects and fixed time effects, which in our estimates yields a lower coefficient. However, while our results imply that the impact of UI benefits is economically important, it is still far too small to reconcile our model with business cycle data. In our model, the ratio $\left(\sigma_{U} / \sigma_{Q}\right) / \epsilon_{\xi}^{U}$ between the relative cyclical volatility of unemployment and the semielasticity of unemployment to UI benefits should be substantially less than one. But in our data, $\left(\sigma_{U} / \sigma_{Q}\right)$ is over seven, and $\epsilon_{\xi}^{U}$ is around two. The standard errors on our policy estimates are not even close to sufficient to reconcile these observations with Proposition 2.

\section{Variations on the standard model}

The version of our model that we characterized analytically in Sec. 3 is strongly rejected by the data we just reviewed. Tinkering with parameters will not help, since the upper bound in Prop. 2 is independent of calibration. However, some generalization of the model might fit better, so we turn next to numerical simulations of the general model from Sec. 2. Our first calibration is chosen to match our estimate of the semielasticity of unemployment with respect to UI benefits, $\epsilon_{\xi}^{U} \approx 2$.

\subsection{Benchmark parameters}

Our benchmark numerical calibration is as follows. All matches have equal productivity $\left(\alpha_{Z}=1\right)$. The productivity shock $Z$ follows a two-state Markov process, taking values $Z^{L O}=-0.018$ and $Z^{H I}=0.018$, and remaining unchanged from one period to the next with probability $\rho_{Z}$. We simulate the model at weekly frequency, but report results aggregated to quarterly frequency. We impose an approximate yearly persistence of 
$\bar{\rho}_{Z} \equiv 2 / 3$, implying business cycles lasting roughly six years, by assuming that $Z$ remains unchanged from one week to the next with probability $\rho_{Z} \equiv \bar{\rho}_{Z}^{1 / 52} \approx 0.9922$.

Search intensity is exogenous: $S=1, h=0$ and $\eta_{S}^{h}=\infty$. The elasticity of total matches to unemployment is $\lambda=0.5$, consistent with Blanchard and Diamond (1989). We assume an efficient benchmark equilibrium, setting $\mu=0.5$ (Hosios 1990). We calibrate an annual job loss rate of approximately $\bar{\delta} \equiv 25 \%$ by setting the weekly probability of job loss to $\delta \equiv \bar{\delta} / 52$. This is reasonable for the US, though separation rates are higher for the least stable classes of jobs and workers. To get an annual discount factor of $\bar{\beta} \equiv 95 \%$, we set the weekly discount factor to $\beta \equiv \bar{\beta}^{1 / 52}$. The matching efficiency and vacancy cost parameters $\gamma$ and $\kappa$ are reset in each simulation so that steady state unemployment is always $U=0.06$ (again, a US calibration) and so that a vacancy lasts two weeks on average. Vacancy duration is just a normalization: doubling it would mean doubling vacancies, reducing $\kappa$ by half, and adjusting $\gamma$ to keep total matches, total vacancy costs, and job finding probabilities unchanged.

On average, the Markov process spends equal time in good and bad states, so mean productivity $y$ is 1 . We set $b=0.745$ and $\tau=0$ in our benchmark calibration: the cost of working is $74.5 \%$ of mean labor productivity, and there are no taxes. These parameters are crucial, because a higher $b$ or $\tau$ implies a smaller and more variable surplus, making unemployment and vacancies more volatile. In fact, (26) shows that the variance of job finding goes to infinity as $b+\tau$ approaches $y+h$ : clearly, the RBCM model cannot be rejected on grounds of insufficient unemployment volatility alone. Setting $b=0.745$ implies $\epsilon_{\xi}^{U}=2$, consistent with our estimates. We set $\tau=0$ for comparison with related studies, but all the effects we obtain by changing $b$ are also implied by changes in $\tau$. Shimer (2005) instead calibrates $b=0.4$, which implies, roughly speaking, that the only cost of working is the loss of the UI benefit. But considering our model, $b$ also includes the utility costs (or any other costs) of working, which are presumably nontrivial.

\section{Benchmark results: importance of the size of the of surplus}

Table 4 shows the simulation results, with the numerical benchmark calibration in line 1. All relative standard deviations and correlations refer to data aggregated to quarterly frequency, and results are HP-filtered with smoothing parameter $100000 .{ }^{17}$

By construction, the long run semielasticity of unemployment with respect to the replacement ratio is $\epsilon_{\xi}^{U}=2.00$ in our numerical benchmark. But this calibration yields

\footnotetext{
${ }^{17}$ The filter has a moderate effect on the absolute level of fluctuations $\sigma_{Q}$, but has virtually no effect on the relative fluctuations $\sigma_{U} / \sigma_{Q}$, which are our focus. The ratio $\sigma_{U} / \sigma_{Q}$ only changes from 1.40 (with filtering) to 1.42 (without). HP filtering would become slightly more relevant if we chose a higher persistence parameter $\bar{\rho}_{Z}$.
} 
insufficient cyclical variation in log unemployment, with $\sigma_{U} / \sigma_{Q}=1.40$, when this ratio is over seven in the data. The punchline is that $\left(\sigma_{U} / \sigma_{Q}\right) / \epsilon_{\xi}^{U}$ equals 0.70 , far too low for consistency with the data, and also well below our analytical upper bound of one. Similar results hold for the job finding probability $p$ : its cyclical variability is $\sigma_{p} / \sigma_{Q}=1.61$ (too low), while the semielasticity $\epsilon_{\xi}^{p}$ is -2.13 (about right; not shown in table). The cyclical variability of vacancies $\sigma_{V} / \sigma_{Q}=3.23$ is also too low.

As we mentioned above, a higher $b$ can increase unemployment variability, by making the surplus smaller and proportionally more volatile. With the benchmark value $b=$ 0.745 , total surplus $\Sigma$ is $45.2 \%$ of the mean quarterly output of a matched worker. In line 2 we set $b=0.955$ (95.5\% of mean $y$ ), which is the cost of working assumed by Hagedorn and Manovskii (2006). This shrinks the surplus $\Sigma$ to just $8.0 \%$ of mean quarterly labor productivity. The relative volatility of unemployment rises to $\sigma_{U} / \sigma_{Q}=5.71$, almost as high as in US data. However, unemployment also becomes more responsive to UI benefits, with $\epsilon_{\xi}^{U}=14.29$, which drastically exceeds our estimates. Intuitively, such a large $b$ means firms own a highly leveraged claim on the productivity process $y$, so that small variations in $y$ or $b$ motivate big changes in hiring.

In line 2, we go in the opposite direction and decrease $b$ to 0.4 , as in Shimer (2005). ${ }^{18}$ Total surplus $\Sigma$ is now $106.3 \%$ of mean quarterly labor productivity. The unemployment semielasticity $\epsilon_{\xi}^{U}$ falls to 0.82 , and the cyclical volatility of unemployment falls to $\sigma_{U} / \sigma_{Q}=0.62$. Thus this calibration not only produces insufficient cyclical volatility: it is even too inelastic to match the estimated impact of UI. Thus we see the main tradeoff: we can make the model more volatile to better match cyclical data, or less volatile to better match labor market data, but the two goals are at odds with each other. In relative terms, the tradeoff is worse when $b$ is large: $\left(\sigma_{U} / \sigma_{Q}\right) / \epsilon_{\xi}^{U}=0.40$ on line 2 , compared with $\left(\sigma_{U} / \sigma_{Q}\right) / \epsilon_{\xi}^{U}=0.76$ on line 3 .

Before moving to other model specifications, we study the effects of several other parameters. In line 4 , we set $\bar{\rho}_{Z}=75 \%$, increasing the length of a full cycle to roughly eight years. In line 5 , we increase the separation rate to $\bar{\delta}=40 \%$ annually, a reasonable US calibration if we prefer to focus on relatively unstable jobs and workers. Line 6 lowers the elasticity of matching with respect to unemployment to $\lambda=0.3$, while maintaining $\mu=0.5$; and line 7 lowers $\mu$ to 0.3 , with $\lambda=0.5$. While there are mild changes in some statistics, the ratio $\left(\sigma_{U} / \sigma_{Q}\right) / \epsilon_{\xi}^{U}$ is robust, staying close to 0.7 in all these experiments.

\footnotetext{
${ }^{18}$ Hall $(2005 B)$ sets $b$ even lower, to $35 \%$ of the firm's flow of surplus in a new match.
} 


\subsection{Variable separation and variable search}

Davis, Haltiwanger, and Schuh (1996) argue that job destruction is strongly countercyclical. Therefore, we need to ask whether variation in separation rates might change our results. The usual model of variable separation (Mortensen and Pissarides 1994) posits a match-specific productivity shock, so that workers and firms separate when their joint surplus becomes negative. For simplicity, we instead assume an exogenous separation rate that depends negatively on the aggregate technology shock, which is essentially what Mortensen and Pissarides' model implies. We set $\bar{\delta}\left(Z^{L O}\right)=0.25 * 1.15=0.2875$ and $\bar{\delta}\left(Z^{H I}\right)=0.25 / 1.15 \approx 0.2174$, so that $\bar{\delta}$ varies with $Z$ by $\pm 15 \%$. Line 8 shows that this brings the cyclicality of unemployment closer to the data: $\sigma_{U} / \sigma_{Q}$ rises to 5.89 . The semielasticity of unemployment with respect to $\xi$ changes only slightly, so the ratio $\left(\sigma_{U} / \sigma_{Q}\right) / \epsilon_{\xi}^{U}$ improves, rising to 2.79 .

The problem is that this way of resolving the conflict destroys the Beveridge curve: the correlation between unemployment and vacancies switches sign to $\rho_{U, V}=0.95$. The fact that variable separation helps increase unemployment volatility, but eliminates the Beveridge curve, has also been noted by Cole and Rogerson (1999) and Shimer (2005). Second, although unemployment becomes more variable, the probability of job finding now varies less: the ratio $\sigma_{p} / \sigma_{Q}$ falls from 1.61 in the numerical benchmark to 1.40 with variable separation. This contradicts Shimer's (2005) calculation that job finding is almost as variable as unemployment. Third, the amount of variation in the separation probability needed here is too large. The relative standard deviation of job destruction to employment is now $\sigma_{D} / \sigma_{N}=13.51$, well above Cole and Rogerson's (1999) figure of six. (In the numerical benchmark, it is exactly one by construction.)

Lines 9 and 19 allow for variable search effort, first considering relatively inelastic search $\left(\eta_{S}^{h}=4\right)$ and then higher elasticity $\left(\eta_{S}^{h}=2\right)$. Variable search effort makes unemployment more cyclical because (as in Sec. 2) search rises when productivity is high. With $\eta_{S}^{h}=4$, we have $\sigma_{U} / \sigma_{Q}=2.75$, while $\eta_{S}^{h}=2$ matches cyclical volatility quite well, reaching $\sigma_{U} / \sigma_{Q}=5.31$. However, the responsiveness of unemployment to benefits rises even more, so that the key ratio $\left(\sigma_{U} / \sigma_{Q}\right) / \epsilon_{\xi}^{U}$ falls. That is, as Props. 1 and 2 indicated, endogenous search only makes the tradeoff worse. Also, sufficiently elastic search effort again destroys the Beveridge curve: with $\eta_{S}^{h}=2$, we have $\rho(U, V)=-0.17{ }^{19}$

\footnotetext{
${ }^{19}$ Merz (1995) also finds that variable search effort acts against the Beveridge curve.
} 


\subsection{Finite UI benefit duration}

Another issue that might matter for our results is our assumption that UI benefits continue as long as unemployment lasts. Intuitively, UI benefits might affect unemployment less if they eventually expired. The easiest way to model finite benefit duration is to assume benefits expire with probability $\phi$ per period, implying expected duration $D \equiv 1 / \phi$. Then there are three labor market states: employed, unemployed with benefits, and unemployed without benefits. The employed workers' Bellman equation (2) is unchanged. ${ }^{20}$ Restricting ourselves to exogenous search effort, equation (3) for the value of unemployment with benefits is replaced by

$W^{U}(Z)=b+\beta E_{Z^{\prime} \mid Z}\left\{p(1, \theta(Z)) W^{E}\left(Z^{\prime}, Z^{\prime}\right)+(1-p(1, \theta(Z)))\left[(1-\phi) W^{U}\left(Z^{\prime}\right)+\phi W^{X}\left(Z^{\prime}\right)\right]\right\}$

where $W^{X}(Z)$ is the value of unemployment without benefits, given by

$$
W^{X}(Z)=b_{0}+\beta E_{Z^{\prime} \mid Z}\left\{p(1, \theta(Z)) W^{E}\left(Z^{\prime}, Z^{\prime}\right)+(1-p(1, \theta(Z))) W^{X}\left(Z^{\prime}\right)\right\}
$$

Here, for the first time, we must distinguish the actual UI benefit $b-b_{0}$ (which expires at rate $\phi$ ) from the disutility of working $b_{0}$. For consistency with the US, we set $b-b_{0}=0.4$.

We first consider a mean benefit duration of six months, which is the US norm. Shorter UI duration increases the employment surplus $\Sigma^{W}=W^{E}-W^{U}$ (this is still the relevant surplus for the Nash wage equation), so with $b=0.745$ the cyclical volatility of unemployment is greatly decreased. Therefore, in line 11 of Table 4 we also change $b$ to 0.87 , which implies roughly the same surplus as in the benchmark of line 1 . The results are similar to those of the numerical benchmark: benefits have a reasonable effect on unemployment, but the cyclical variability of unemployment is much too small, so the key ratio $\left(\sigma_{U} / \sigma_{Q}\right) / \epsilon_{\xi}^{U}$ only increases from 0.7 in line 1 to 0.79 in line 11 . In line 12 , we instead assume benefits last two years, which is the median duration reported for European countries in LN99. This time we adjust $b$ to 0.80 to keep the size of the surplus in line with the benchmark model. Results are again similar.

Thus finite benefit duration does not affect our main results. However, it does give us an additional way to test the model, using LN99's estimate of the semielasticity of

\footnotetext{
${ }^{20}$ This assumes workers become eligible for UI from the moment of matching. Otherwise there would be a fourth labor market state, employed without benefits, with a lower outside option and thus lower wages. As Coles and Masters (2005) point out, this would drive down wages of new jobs in recessions (when more workers run out of benefits), making unemployment even less volatile.
} 
unemployment with respect to benefit duration, $\epsilon_{D}^{U}=0.1 .^{21}$ Since the cyclical variability of unemployment is roughly 7 , the ratio $\left(\sigma_{U} / \sigma_{Q}\right) / \epsilon_{D}^{U}$ should be around 70 . Instead, the final column of lines 11 and 12 reports values of 7.33 and 11.27 , respectively: $\sigma_{U} / \sigma_{Q}$ is too small compared with the effect of duration on the unemployment rate. Thus considering finite benefit duration reinforces our claim that the standard RBCM framework understates cyclical volatility relative to the effects of policies.

\subsection{Sticky wages}

We have seen that higher $b$ means higher percentage variation in the firm's surplus over the cycle, increasing the variability of hiring and unemployment. Another obvious way to make the firm's surplus volatile would be to impose some form of wage stickiness, as has been advocated recently by Shimer (2004) and Hall (2005A,B). Furthermore, it seems natural to assume that sticky wages are only a short run phenomenon, so that they should have minimal influence on the long run impact of the UI benefit.

Again, we choose an easy ad hoc way of making wages sticky. We assume that workers' bargaining power varies negatively with the technology shock, so that workers get a larger share of surplus in recessions. This stabilizes the wage over the cycle, and thus destabilizes the firm's hiring incentives. In line 13 we assume that the worker's bargaining power increases (decreases) by $15 \%$ when the aggregate technology shock is low (high). This raises $\sigma_{U} / \sigma_{Q}$ to 5.67 , roughly consistent with the data. The semielasticity $\epsilon_{\xi}^{U}$ hardly changes, so that $\left(\sigma_{U} / \sigma_{Q}\right) / \epsilon_{\xi}^{U}$ increases to 2.73 .

This does not seem like an unreasonable degree of wage stickiness: the ratio of the standard deviations of $\log$ wages and $\log$ output is now $\sigma_{w} / \sigma_{Q}=0.59$. This is better than the figure of 0.91 in the baseline model, though still not as low as in the data; for example, Merz (1995) reports $\sigma_{w} / \sigma_{Q}=0.37$ for the US. Therefore, sticky wages seem a potentially promising way of improving the model's fit. But obviously they are controversial, and debate goes on about possible justifications for wage stickiness.

One possible microfoundation for wage stickiness is an "efficiency wage". Here, if we follow Shapiro and Stiglitz (1984) by assuming a constant probability of catching shirkers, firms should offer workers a constant surplus just sufficient to prevent shirking. ${ }^{22}$

\footnotetext{
${ }^{21}$ See their Table 15. Here we refer to LN99's estimate because their duration variable, the number of years benefits last, can be interpreted as $D=1 / \phi$ in our model. Our own duration regressor is the fraction of benefits remaining after the first year, which is harder to interpret in terms of (30)-(31). But since it is insignificant in our regressions, the conclusion remains that UI duration has stronger effects in the model than in the data.

${ }^{22}$ Costain and Jansen (2006) provide a more complete analysis of the cyclical dynamics of a matching model with efficiency wages.
} 
Thus in line 14 we report a version of our model where the Nash bargaining condition (8) is replaced by an equation that fixes a constant surplus for the worker at all times (equal to the average surplus in the numerical benchmark of line 1). While cyclical unemployment volatility rises, the semielasticity of $U$ with respect to $\xi$ increases even more, so that $\left(\sigma_{U} / \sigma_{Q}\right) / \epsilon_{\xi}^{U}$ falls to 0.64 . The problem is that the possibility of shirking alters wages not only in the short run, but also in the long run. Imposing a constant surplus for the worker makes hiring incentives fall sharply with the replacement ratio, so that our efficiency wage model fits less well than our ad hoc sticky wage model, in which wages adjust flexibly to long run changes in UI.

\subsection{Cohort-specific technology shocks}

Finally, we show that a form of embodied technological change could also help solve the puzzle that concerns us. If it is cheaper to start using a new technology by hiring new workers with different skills instead of retraining existing employees, then technology shocks should affect new matches without changing the productivity of old ones. ${ }^{23}$ One reason to prefer such a specification is that, in contrast to the model of Sec. 3, it makes wages of new hires more procyclical than those of continuing jobs. This is a wellestablished empirical fact (see for example Bils 1985 and Bowlus 1995). There is also direct evidence that workers find higher-quality jobs in booms than in recessions, from data on movements across sectors (Heckman and Sedlacek 1985), job tenure (Bowlus 1995), and worker and job characteristics (Devereux 2003). Again, this suggests that productivity should have a match-specific or cohort-specific component.

So we next set $\alpha_{Z}=0$, making the productivity of each match specific to its time of creation. Since shocks no longer affect all matches equally, the persistence of aggregate output increases, so we decrease the persistence parameter $\bar{\rho}_{Z}$ from 0.67 to 0.6 annually. We also initially set $\zeta=1$, so that the cohort-specific shock has the same impact as the aggregate shock did; and we lower $b$ slightly to 0.7 , to keep $\epsilon_{\xi}^{U}$ near its target level of two. This simple change of specification, called the "cohort-specific benchmark" in the table, more than suffices to reconcile cyclical unemployment volatility with the effect of policy on unemployment. In line 15 , we find that $\sigma_{U} / \sigma_{Q}=9.66$, even higher than in the data, while $\epsilon_{\xi}^{U}=1.79$ is slightly decreased, so that the ratio $\left(\sigma_{U} / \sigma_{Q}\right) / \epsilon_{\xi}^{U}$ rises to $5.40 .{ }^{24}$ The job finding probability also varies more: $\sigma_{p} / \sigma_{Q}=11.32$.

\footnotetext{
${ }^{23}$ Mortensen and Pissarides (1998) and Hornstein, Krusell, and Violante (2005B) study trend growth in models where employers can implement new technology by retraining or by rehiring.

${ }^{24}$ Since fluctuations are more persistent under this specification, the results are now more sensitive to the HP filter. Without filtering, we have $\sigma_{U} / \sigma_{Q}=7.86$ instead of 9.66 , but this still suffices to match the data.
} 
Why does this cohort-specific productivity specification increase cyclical volatility so much? Note that when technology shocks are disembodied $\left(\alpha_{Z}=1\right)$ and thus immediately affect all matches, workers and firms know that a high match productivity $Z$ may fall before separation, and a low $Z$ may rise. In contrast, in the embodied $\left(\alpha_{Z}=0\right)$ case, a match's productivity $z$ will be unchanged until separation; other things equal, this increases the difference in value between high and low productivity matches, making hiring respond more strongly to the aggregate state. Also, since employment now varies more relative to output, and high and low productivity matches coexist, we now find that aggregate productivity varies less relative to output than it did with disembodied productivity: $\sigma_{y} / \sigma_{Q}$ falls from 0.92 in the model of line 1 to 0.54 in the cohort-specific benchmark of line 15. This also improves the model's fit, though it goes somewhat too far, overshooting the ratio $\sigma_{y} / \sigma_{Q}=0.65$ we calculate from the FRED data.

A potential problem with the embodied technology specification is that wages become much more volatile: $\sigma_{w} / \sigma_{Q}$ more than triples from its benchmark value in line 1 , which is already too high. The reason is that even though a technological improvement leaves the productivity of existing matches unchanged, it nonetheless raises all workers' outside options, and thereby their wages. We should emphasize here that matching models do not actually tie down the wage process. These models only specify how the surplus is split between the firm and worker, and more than one wage process (including, for example, implicit contracts that keep the wages of existing matches fixed) is consistent with the implied behavior of the surplus. ${ }^{25}$ Therefore we may not want to reject this model on the basis of its wage implications. However, those who wish to take wage data literally may prefer the sticky wage model of line 13 .

Since assuming entirely embodied technology exaggerates unemployment fluctuations and also understates aggregate productivity fluctuations, we can now afford to go to the intermediate case $\alpha_{Z}=0.5$, so that technology shocks have both aggregate and cohort-specific effects. To do well on both these margins simultaneously, it is also helpful to raise $\zeta$ to 1.6, making embodied technology shocks $60 \%$ stronger than disembodied shocks. This parameterization is shown in line 16, with labor market cyclicality $\left(\sigma_{U} / \sigma_{Q}=5.36\right)$ and policy effects $\left(\epsilon_{\xi}^{U}=1.77\right)$ both close to the data.

Finally, since output differs across matches, it now seems especially important to consider variable separation. Thus in line 17 we vary the separation rate by $\pm 10 \%$ with the match-specific shock $z$ : that is, we assume less productive matches are always more

\footnotetext{
${ }^{25}$ Two papers exploring implicit contracts are Rudanko (2005) and Reiter (2006), which studies our embodied technology specification in greater depth. In both papers, aggregate wages become even smoother than they are in US data.
} 
likely to separate. This specification yields our most successful simulation. The ratio $\sigma_{U} / \sigma_{Q}$ rises to 6.43 , and the semielasticity of unemployment with respect to the replacement ratio $\xi$ is nearly unchanged at $\epsilon_{\xi}^{U}=1.80$, so that $\left(\sigma_{U} / \sigma_{Q}\right) / \epsilon_{\xi}^{U}=3.58$ is consistent with the data. While line 8 showed that generating labor market volatility through variable separation alone reverses the sign of the Beveridge correlation, combining variable separation with another source of labor market volatility only mildly reduces the correlation between unemployment and vacancies, to -0.60 . This version of the model is also fairly successful with the volatility of labor productivity: $\sigma_{y} / \sigma_{Q}$ equals 0.60 in our model and 0.65 in our data; the job finding probability: $\sigma_{p}$ equals 10.5 in our model and 11.8 in the data of Shimer (2005); and job destruction: $\sigma_{J D} / \sigma_{N}$ equals 3.36 in our model and 6.57 in the data of Cole and Rogerson (1999). The biggest problem with this specification is again excessive wage variability, $\sigma_{w} / \sigma_{Q}=2.43$.

\section{Matching in business cycle models with capital}

We have argued that our model's lack of physical capital is probably inessential for our results. But to be sure, we finish by reexamining the models of Merz (1995) and Andolfatto (1996), which include capital. While these papers reported some success in modeling labor market fluctuations, when we recalculate their steady states to measure the effects of UI benefits, we find that they suffer from the same problem as our benchmark model: insufficient cyclical volatility compared with the impact of policy.

\subsection{The model of Andolfatto (1996)}

To understand both models it is helpful to start by looking at the surplus. In Andolfatto's case, we calculate that the match surplus is equal to only $17.3 \%$ of mean quarterly labor productivity - much lower than that of our numerical benchmark. ${ }^{26}$ This suggests that his labor market should be quite volatile.

At first glance, Andolfatto's labor market appears to work well. His Table 1 shows that employment is 0.51 times as variable as output in his model, compared with 0.67 in his data. However, this hides a surprising failure to explain unemployment, because of an unusual calibration. Andolfatto sets the mean employment rate to $57 \%$, so that the mean unemployment rate is $43 \%$, thus treating any nonworking person over age 16 as

\footnotetext{
${ }^{26}$ In Andolfatto's notation, from $q J=\kappa$ and $J=\alpha \Sigma$ we get the total surplus as $\Sigma=\kappa /(q \alpha)=$ $0.105 /(0.9 * 0.6)=0.194$ in units of quarterly output. (This equals $\mu$, the shadow value of a match, divided by the marginal utility of consumption.) Labor productivity is $(1-\theta) y / n=0.64 / 0.57=1.123$, so match surplus is $0.194 / 1.123=17.3 \%$ of quarterly productivity.
} 
unemployed. This goes far beyond some authors, such as Cole and Rogerson (1999) and den Haan et. al. (2000), who have argued for a broader definition of unemployment, by including all pensioners, students, and homemakers as inputs to the matching function. Any given standard deviation of log employment therefore corresponds to a smaller standard deviation of log unemployment in Andolfatto's calibration than it would if baseline unemployment were lower. With his numbers, we find:

$$
\frac{\sigma_{U}}{\sigma_{Q}}=\frac{1-U}{U} \frac{\sigma_{N}}{\sigma_{Q}}=\left(\frac{0.57}{0.43}\right) 0.51=0.68
$$

less than one tenth of the volatility we calculate from US data, based on the standard definition of unemployment.

Furthermore, even if we choose to ignore unemployment, Andolfatto's model also understates the volatility of other labor market variables. The coefficient of variation of vacancies in his model is about $4.4 \%$, so that $\sigma_{V} / \sigma_{Q}=3.2$, compared to 9 in his data. Since unemployment hardly varies, the coefficient of variation of tightness is only slightly higher (4.6\%), compared with $37 \%$ in our data. Using $1-\lambda=0.6$, workers' job finding probability has coefficient of variation $0.6 * 4.6 \%=2.8 \%$ in Andolfatto's model, about one fourth of the volatility Shimer (2005) finds in US data.

Andolfatto's model has no UI benefits, but in his setup they would be equivalent to work disutility. Thus, to mimic a one percentage point increase in the UI replacement ratio, we raise the utility of the nonemployed by one percent of mean labor productivity, scaled by the marginal utility of consumption. We calculate that the semielasticity of unemployment with respect to the replacement ratio is 2.41 in Andolfatto's model, which might seem consistent with our cross-country estimate. But it is not: given Andolfatto's interpretation of unemployment, each $1 \%$ increase in $\log U$ represents a 0.43 percentage point increase in unemployment. That is, a one percentage point rise in the replacement ratio increases unemployment by $2.41 * 0.43=1.04$ percentage points, whereas Layard et. al. (1991) estimate that this coefficient is $0.17 .{ }^{27}$ Seen in this way, Andolfatto's labor market both behaves too smoothly over the business cycle, and overreacts to UI; the punchline for his paper is $\left(\sigma_{U} / \sigma_{Q}\right) / \epsilon_{\xi}^{U}=\frac{0.68}{2.41}=0.28$.

\subsection{The model of Merz (1995)}

Merz (1995) comes close to fitting the variability of unemployment and the job finding probability in US data. With her benchmark specification, $\sigma_{U} / \sigma_{Q}=4.77,{ }^{28}$ and $\sigma_{p} / \sigma_{Q}=$

\footnotetext{
${ }^{27}$ Here, for comparability, we refer to a slope estimate instead of a semielasticity estimate.

${ }^{28}$ This is the result of our own calculation and differs slightly from the number in Merz' Table 2.
} 
5.41. However, if we back out the effect of UI in the same way we did for Andolfatto, we find that the model exaggerates the sensitivity of unemployment to benefits. yielding a semielasticity of 6.54 . The statistic $\frac{\sigma_{U}}{\sigma_{Q}} \frac{1}{\epsilon_{\xi}^{U}}$ is therefore 0.73 , so Merz' model fails by roughly the same factor as our benchmark model in Section 4.1.

When we calculate the match surplus in Merz' model, it turns out to be only 1.69 percent of mean quarterly labor productivity - five times smaller than anything we have seen so far. Thus Merz achieves sufficient cyclical volatility only by assuming an almost negligible surplus, and in doing so exaggerates the response to UI benefits.

The reason Merz' labor market fluctuates so little, in relation to the tiny surplus she assumes, is that she defines the surplus differently from all the other models we have discussed. Most matching models assume that the marginal disutility of work is constant along the extensive margin (increases in employment) even if it is increasing along the intensive margin (increasing marginal disutility in hours per job, as in Andolfatto's model). In contrast, in Merz' paper the surplus accrues to a family with a continuum of members, with increasing marginal disutility of work as more family members find jobs. At the margin, the disutility from one more job almost equals the wage income from that job, so the surplus is extremely small. To us, the usual formulation seems more appropriate, since typical households contain only one or two earners, each of whom may have a large inframarginal gain when they find a job.

\subsection{Other models with capital}

Den Haan et. al. (2000) study an RBCM model with endogenous separations. They are successful in explaining variations in job creation and destruction, and find that the interaction between job destruction and investment helps amplify shocks. This is consistent with our finding that variable separation can make matching volatile. However, our calculations suggest that their model will fail to generate a Beveridge curve. Their paper does not report the correlation between vacancies and unemployment. ${ }^{29}$

Gomes et. al. (2001) simulate a business cycle model in which individuals search for jobs. It is not an RBCM model, because it has no matching function. Instead, it has an exogenous distribution of job offers, making it a dynamic extension of McCall's (1970) partial equilibrium search model. They successfully reproduce the cyclical fluctuations of unemployment. However, they state that raising the replacement ratio from 0.5 to 0.7 increases unemployment from $6.1 \%$ to $13.9 \%$, which is a semielasticity of 6.49 , exceeding our estimate by a factor of three. Thus their model suffers from the same problem as the RBCM models we have addressed.

\footnotetext{
${ }^{29}$ Fujita (2003) explores ways of extending the den Haan et. al. model to generate a Beveridge curve.
} 


\section{Conclusions}

A model of real business cycles and matching implies that job creation depends on the surplus available to the matched pair. Procyclical employment fluctuations occur if surplus rises in booms, and increased unemployment benefits drive down employment by decreasing the surplus. The standard RBCM model implies a close relationship between these two aspects of employment variability, which is strongly at odds with data. To fit business cycle data, the surplus must be small enough so that productivity shocks have a big effect on vacancies; but to reproduce the observed effects of policies, the surplus must be large enough so that UI benefits have a small effect on vacancies. We have shown analytically that these two requirements cannot be reconciled in a baseline version of the model. We have shown numerically that this result is robust to endogenous search, endogenous separation, finite benefit duration, and efficiency wages; we have also argued that capital, variable benefits, and variable hiring costs are unlikely to resolve the puzzle; and we have argued that the HP filter is not crucial for our results.

Match-embodied technological change can help reconcile these two implications of the model (see also Hornstein et. al. 2005), because it makes the surplus accruing to the firm substantially more procyclical, so that hiring, unemployment, and the worker's job-finding probability all fluctuate more. Sticky wages have a similar effect on the firm's surplus, so they also help increase cyclical variability without exaggerating the impact of labor market policy (see also Shimer 2004; Hall 2005B; Gertler and Trigari 2005; Menzio 2005).

Our findings suggest that modeling labor market fluctuations by calibrating a very small match surplus, as Hagedorn and Manovskii (2006) advocate, is unhelpful because it is inconsistent with robust observations about the effects of labor market policy. There is endless scope for debating cross-country regressions, but we find that the small surplus calibration must take us far from any available evidence on policy effects in order to reproduce cyclical fluctuations. While sticky wages or embodied productivity shocks may prove to be fruitful explanations of labor market dynamics, many other ways of improving the fit of the matching model have also been suggested recently, including alternative specifications of the bargaining game, hiring and training costs, and shocks to job destruction (Hall and Milgrom 2005; Silva and Toledo 2005; Mortensen and Nagypál 2006). In the long run we believe economists will learn a lot about the labor market and business cycles by asking which of these alternatives are consistent with a wide range of empirical facts. More generally, we believe policy studies are often likely to be useful in testing business cycle models: measuring the impact of observable policy shocks may impose useful discipline on business cycle models where the shocks might otherwise have 
to be treated as unobservables. This sort of discipline seems especially important if the models in question are intended for use in policy analysis.

\section{Appendix 1: Linearized dynamics}

First we linearize the zero profit condition (18) and the dynamics of the surplus (17):

$$
\begin{gathered}
\lambda \tilde{\theta}_{t}-\tilde{S}_{t}=\lambda^{*} \tilde{\theta}_{t}=E_{t} \tilde{\Sigma}_{t+1} \\
\tilde{\Sigma}_{t}=\frac{y}{\Sigma} \tilde{y}_{t}+\beta(1-\delta-\mu p) E_{t} \tilde{\Sigma}_{t+1}-\beta \mu p \tilde{p}_{t}+\frac{h}{\Sigma} \eta_{S}^{h} \tilde{S}_{t}
\end{gathered}
$$

These equations can be simplified by writing $\tilde{p}_{t}$ and $\tilde{S}_{t}$ in terms of $\tilde{\theta}_{t}$ and $E_{t} \tilde{\Sigma}_{t+1}$, as follows: $\tilde{p}_{t}=\left(1-\lambda^{*}\right) \tilde{\theta}_{t}$, and $\tilde{S}_{t}=\eta_{\theta}^{S} \tilde{\theta}_{t}$, and $\tilde{\theta}_{t}=\frac{1}{\lambda^{*}} E_{t} \tilde{\Sigma}_{t+1}$. The following matrix system summarizes the dynamics of $\tilde{y}$ and $\tilde{\Sigma}$ :

$\left(\begin{array}{c}E_{t} \tilde{y}_{t+1} \\ E_{t} \tilde{\Sigma}_{t+1}\end{array}\right)=\left(\begin{array}{c}\rho \\ -\frac{y}{\Sigma}\left[\beta\left(1-\delta-\frac{\mu p}{\lambda^{*}}\right)+\frac{h \eta_{S}^{h} \eta_{\theta}^{S}}{\Sigma \lambda^{*}}\right]^{-1}\left[\beta\left(1-\delta-\frac{\mu p}{\lambda^{*}}\right)+\frac{h \eta_{S}^{h} \eta_{\theta}^{S}}{\Sigma \lambda^{*}}\right]^{-1}\end{array}\right)\left(\begin{array}{c}\tilde{y}_{t} \\ \tilde{\Sigma}_{t}\end{array}\right)$

The eigenvalues are $0<\rho<1$ and $\left[\beta\left(1-\delta-\frac{\mu p}{\lambda^{*}}\right)+\frac{h \eta_{S}^{h} \eta_{\theta}^{S}}{\Sigma \lambda^{*}}\right]^{-1}$. We assume search is sufficiently inelastic so that the second eigenvalue is greater than one (this is automatically true if search is exogenous). ${ }^{30}$ Thus the system is saddle-path stable, and has a unique equilibrium. The eigenvector associated with the stable eigenvalue can be written as $(1 x)^{\prime}$, where

$$
x \equiv \frac{y}{\Sigma\left(1-\rho\left[\beta\left(1-\delta-\mu \frac{p}{\lambda^{*}}\right)+\frac{h \eta_{S}^{h} \eta_{\theta}^{S}}{\Sigma \lambda^{*}}\right]\right)}
$$

Using the steady state surplus equation (20), this can be written as

$$
x=\left(\frac{y}{y-b-\tau+h}\right)\left[\frac{1-\beta+\beta \delta+\beta \mu p}{1-\rho \beta+\rho \beta \delta+\rho \beta \mu p / \lambda^{*}-\rho h \eta_{S}^{h} \eta_{\theta}^{S} /\left(\Sigma \lambda^{*}\right)}\right]
$$

Saddle path stability implies that $x$ is the elasticity $\tilde{\Sigma}_{t} / \tilde{y}_{t}$. Thus, in terms of the observable variable $\tilde{p}$, we have:

$$
\tilde{p}_{t}=\left(1-\lambda^{*}\right) \tilde{\theta}_{t}=\frac{1-\lambda^{*}}{\lambda^{*}} E_{t} \tilde{\Sigma}_{t+1}=\frac{1-\lambda^{*}}{\lambda^{*}} \rho x \tilde{y}_{t}
$$

Again we see that sufficiently inelastic search $\left(\lambda^{*}>0\right)$ is essential for matching the data: (38) shows that the job finding probability is decreasing in productivity if $\lambda^{*}<0$.

\footnotetext{
${ }^{30}$ We assume periods are short enough so that $p$ is small, which means this eigenvalue is positive.
} 
Now using formula (37) for $x$, we obtain equation (26), which is used to derive Prop. 1. For Prop. 2, we linearize the dynamics (28) of unemployment:

$$
\tilde{U}_{t+1}=(1-\delta) \tilde{U}_{t}-\delta\left(\frac{1-U}{U}\right)\left(1-\lambda^{*}\right) \tilde{\theta}_{t}-\delta\left(\frac{1-U}{U}\right) \tilde{U}_{t}
$$

On the saddle path, we have:

$$
\tilde{\theta}_{t}=\frac{1}{\lambda^{*}} E_{t} \tilde{\Sigma}_{t+1}=\frac{1}{\lambda^{*}} \rho \tilde{\Sigma}_{t}=\frac{1}{\lambda^{*}} \rho x \tilde{y}_{t}
$$

so the dynamics of $U$ become $\tilde{U}_{t+1}=A \tilde{U}_{t}-B \tilde{y}_{t}$, where we define $A \equiv(U-\delta) / U$ and $B \equiv \delta\left((1-U)\left(1-\lambda^{*}\right) /\left(U \lambda^{*}\right)\right) \rho x$. This implies:

$$
\operatorname{Var}\left(\tilde{U}_{t}\right)=\frac{B^{2}(1+\rho A)}{\left(1-A^{2}\right)(1-\rho A)} \operatorname{Var}\left(\tilde{y}_{t}\right)
$$

which simplifies to:

$$
\frac{\sigma_{U}}{\sigma_{y}} \equiv \sqrt{\frac{\operatorname{Var}\left(\tilde{U}_{t}\right)}{\operatorname{Var}\left(\tilde{y}_{t}\right)}}=\rho x(1-U)\left(\frac{1-\lambda^{*}}{\lambda^{*}}\right) \sqrt{\frac{\delta(U+\rho(U-\delta))}{(2 U-\delta)(U+\rho(\delta-U))}}
$$

This equation, together with the formula (37) for $x$, and the formula (23) for the steady state comparative statics, gives us Proposition 2.

\section{Appendix 2: Data}

Data sources. We study two data sets. First, we obtained the Labor Market Institutions Database (LMIDB), compiled by Steven Nickell and Luca Nunziata, from the webpage of the Centre for Economic Performance (it is an appendix to CEP Discussion Paper \#502). The LMIDB database is constructed from OECD data on institutional and labor market characteristics of 20 countries for 1960-94.

Our second dataset includes extensions of the LMIDB database added first by the IMF and then by Baker, Glyn, Howard, and Schmitt (BGHS). This dataset, available on the webpage of John Schmitt at the CEPR, extends most series to 1999 and includes some additional or alternative variables. When the BGHS data we need only exist up to 1997 or 1998, we extend the data to 1999 using the last available value.

Sample. The LMIDB and BGHS data sets include annual data from 1960 to 1994 and 1999, respectively, for Australia, Austria, Belgium, Canada, Denmark, Finland, France, Germany (including East from 1989 on), Ireland, Italy, Japan, Netherlands, New Zealand, Norway, Portugal, Spain, Sweden, Switzerland, the UK, and the US. 
Before running our regressions, we average each variable, for each country, over fiveyear periods from 1960-64 to 1995-99. We exclude Portugal because of missing data, so in most regressions our panel contains 19 countries and 8 time periods.

Variable definitions. Except where stated otherwise, the following variables are identical to those in Nickell and Nunziata (2001), which can be consulted for further details. Log unemployment rate. To construct our dependent variable, we first average the unemployment rate over 5-year periods, and then take the log.

Tax wedge. This is the sum of three tax rates: employers' contributions as a fraction of payments to labor, plus direct taxes as a fraction of household income, plus indirect taxes as a fraction of private expenditures. In our regressions we multiply this fraction by 100 to convert it to a percentage, for comparability with LN99, Table 15.

UI benefit replacement ratio. Initial UI benefits as a fraction of gross wage income. We multiply it by 100 to convert it to a percentage, for comparability with LN99. In some regressions, instead of including the tax wedge and UI benefit replacement ratio separately, we include their sum.

Benefit duration. This expresses UI benefits after the first year as a fraction of initial benefits $b$. If $b_{23}$ is the benefit level in the second and third years of unemployment, and $b_{45}$ is the level in the fourth and fifth years, benefit duration is $b^{-1}\left(0.6 b_{23}+0.4 b_{45}\right)$.

Employment protection. This is an index of the extent of legal impediments to firing, taking values from 0 (weak employment protection laws) to 2 (strong). We multiply it by 10 so that it is an index from 0 to 20, as in LN99.

Union density. This is the fraction of workers who are union members. We multiply it by 100 to convert it to a percentage, as in LN99.

Bargaining coordination. This is an index representing the extent to which wage bargaining is coordinated at a nationwide level, taking values from 0 (no coordination) to 3. We multiply it by 2 , making it an index from 0 to 6 , as in LN99.

Owner occupancy rate. This represents the fraction of households who own their homes. We multiply it by 100 to convert it to a percentage, as in LN99.

Active labor market policies (ALMP). This variable, available in the BGHS data but not the LMIDB, represents the fraction of GDP, per unemployed worker, spent by the government on job training and job matching. Since dividing by the unemployment rate causes an endogeneity problem, we also construct an instrument in which the fraction of GDP spent on ALMP is divided by the unemployment rate in the previous five-year period. ALMP is only available from 1985 to 1999, with some missing values which we have filled in by interpolation.

Mean output gap. This variable, available in the BGHS data but not the LMIDB, is an OECD estimate of the output gap as a fraction of GDP (positive when output is 
above potential). We never use this as a country-specific variable; instead, we include its (unweighted) cross-country mean as an alternative to including time dummies.

Web page. Our data files can be downloaded from the following web page:

http://www.econ.upf.es/ costain/rbcmatch/webpage/bcui.html

This page also includes step-by-step information about the construction of our data set, STATA commands for running our regressions, and many regression results.

\section{References}

Andolfatto, D., 1996. Business Cycles and Labor Market Search, American Economic Review 86 (1), 112-132.

Atkinson, A., Micklewright, J., 1991. Unemployment Compensation and Labor Market Transitions: A Critical Review. Journal of Economic Literature 29 (4), 1679-1727.

Baker, D., Glyn, A., Howell, D., Schmitt, J., 2003. Labor Market Institutions and Unemployment: a Critical Assessment of the Cross-Country Evidence. Center for European Studies Working Paper \#98.

Baker, D., Glyn, A., Howell, D., Schmitt, J., 2004. Unemployment and Labor Market Institutions: the Failure of the Empirical Case for Deregulation. Schwartz Center Working Paper \#2004-4.

Belot, M., van Ours, J., 2004. Does the Recent Success of Some OECD Countries in Lowering their Unemployment Rates Lie in the Clever Design of their Labor Market Reforms? Oxford Economic Papers 56 (4), 621-642.

Bennmarker, H., Carling, K., Holmlund, B., 2005. Do Benefit Hikes Damage Job Finding? Evidence from Swedish Unemployment Insurance Reforms. CESifo Working Paper \#1460.

Bertola, G., Blau, F., Kahn, L., 2001. Comparative Analysis of Labor Market Outcomes: Lessons for the United States from International Long-Run Evidence, in: Krueger, A., Solow, R., (Eds.), The Roaring Nineties: Can Full Employment be Sustained? Russell Sage Foundation, New York.

Bils, M., 1985. Real Wages over the Business Cycle: Evidence from Panel Data. Journal of Political Economy 93 (4), 666-689. 
Blanchard, O., Diamond, P., 1989. The Beveridge Curve. Brookings Papers on Economic Activity 0 (1), 1-60.

Blanchard, O., Wolfers, J., 2000. The Role of Shocks and Institutions in the Rise of European Unemployment: the Aggregate Evidence. Economic Journal 110, pp. C1C33.

Bowlus, A., 1995. Matching Workers and Jobs: Cyclical Fluctuations in Match Quality. Journal of Labor Economics 13 (2), 335-350.

Cole, H., Rogerson, R., 1999. Can the Mortensen-Pissarides Matching Model Match the Business Cycle Facts? International Economic Review 40 (4), 933-959.

Coles, M., Masters, A., 2005. Re-entitlement Effects with Duration Dependent Unemployment Insurance in a Stochastic Matching Equilibrium. Manuscript, SUNY Albany.

Costain, J., Jansen, M., 2006. Employment Fluctuations with Downward Wage Rigidity: the Role of Moral Hazard. Manuscript, Bank of Spain.

Davis, S., Haltiwanger, J., Schuh, S., 1996. Job Creation and Destruction. MIT Press, Cambridge, Mass.

Den Haan, W., Ramey, G., Watson, J., 2000. Job Destruction and the Propagation of Shocks, American Economic Review 90, 482-498.

Devereux, P., 2003. Cyclical Quality Adjustment in the Labor Market. Southern Economic Journal 70 (3), 600-615.

Disney, R., 2000. The Impact of Tax and Welfare Policies on Employment and Unemployment in OECD Countries. IMF Working Paper WP/00/64.

Elmeskov, J., Martin, J., Scarpetta, S., 1998. Key Lessons for Labor Market Reforms: Evidence from OECD Countries' Experience. Swedish Economic Policy Review 5 (2), 205-252.

Fitoussi, J., Jestaz, D., Phelps, E., Zoega, G., 2000. Roots of the Recent Recoveries: Labor Reforms or Private Sector Forces? Brookings Papers on Economic Activity 2000 (1), 237-311.

Fujita, S., 2003. The Beveridge Curve, Job Creation, and the Propagation of Shocks. Manuscript, Univ. of California at San Diego. 
Fujita, S., 2004. Vacancy Persistence. Federal Reserve Bank of Philadelphia Working Paper 04-23.

Gomes, J., Greenwood, J., Rebelo, S., 2001. Equilibrium Unemployment. Journal of Monetary Economics 48, 109-152.

Hagedorn, M., Manovskii, I., 2006. The Cyclical Behavior of Equilibrium Unemployment and Vacancies Revisited. Manuscript, Univ. of Pennsylvania.

Hall, R., 2003. Modern Theory of Unemployment Fluctuations: Empirics and Policy Applications. American Economic Review Papers and Proceedings 93 (2), 145-150.

Hall, R., 2005A. Employment Efficiency and Sticky Wages: Evidence from Flows in the Labor Market. Review of Economics and Statistics 87 (3), 397-405.

Hall, R., 2005B. Employment Fluctuations with Equilibrium Wage Stickiness. American Economic Review 95 (1), 50-65.

Hall, R., Milgrom, P., 2005. The Limited Influence of Unemployment on the Wage Bargain. NBER Working Paper \#11245.

Heckman, J., Sedlacek, G., 1985. Heterogeneity, Aggregation, and Market Wage Functions: An Empirical Model of Self-selection in the Labor Market. Journal of Political Economy 93 (6), 1077-1125.

Hornstein, A., Krusell, P., Violante, G., 2005A. Unemployment and Vacancy Fluctuations in the Matching Model: Inspecting the Mechanism. Federal Reserve Bank of Richmond Economic Quarterly 91 (3), 19-51.

Hornstein, A., Krusell, P., Violante, G., 2005B. The Replacement Problem in Frictional Economies: A Near Equivalence Result. Journal of the European Economic Association 3, 765-775.

Hosios, A., 1990. On the Efficiency of Matching and Related Models of Search and Unemployment, Review of Economic Studies 57 (2), 360-399.

Hunt, J., 1995. The Effect of Unemployment Compensation on Unemployment Duration in Germany. Journal of Labor Economics 13 (1), 88-120.

International Monetary Fund, 2003. Unemployment and Labor Market Institutions: Why Reforms Pay Off. Ch. 4 of World Economic Outlook, April 2003, 129-150. 
Layard, R., Nickell, S., Jackman, R., 1991. Unemployment: Macroeconomic Performance and the Labour Market, Oxford Univ. Press, Oxford.

McCall, J., 1970. Economics of Information and Job Search. Quarterly Journal of Economics 84, 113-126.

Menzio, G., 2005. High-Frequency Wage Rigidity. Manuscript, Univ. of Pennsylvania.

Merz, M., 1995. Search in the Labor market and the Real Business Cycle. Journal of Monetary Economics 36, 269-300.

Millard, S., Scott, A., Sensier, M., 1997. The Labour Market over the Business Cycle: Can Theory Fit the Facts? Oxford Review of Economic Policy 13 (3), 70-92.

Mortensen, D., Nagypál, E., 2006. More on Unemployment and Vacancy Fluctuations. Manuscript, Northwestern Univ.

Mortensen, D., Pissarides, C., 1994. Job Creation and Job Destruction in the Theory of Unemployment, Review of Economic Studies 61 (3), 397-415.

Mortensen, D., Pissarides, C., 1998. Technological Progress, Job Creation, and Job Destruction. Review of Economic Dynamics 1, 733-753.

Nickell, S., Layard, R., 1999. Labor Market Institutions and Economic Performance, in: Ashenfelter, O., Card, D., (Eds.), Handbook of Labor Economics, v.3c; NorthHolland, Amsterdam.

Nickell, S., Nunziata, L., 2001. Labor Market Institutions Database. Manuscript, London School of Economics.

Nickell, S., Nunziata, L., Ochel, W., 2005. Unemployment in the OECD since the 1960s. What Do We Know? Economic Journal 115 (1), 1-27.

Pissarides, C., 2000. Equilibrium Unemployment Theory, 2nd ed. Blackwell, Cambridge, Mass.

Ravn, M., 2006. The Consumption-Tightness Puzzle. Manuscript, European University Institute.

Reiter, M., 2006. Embodied Technical Change and the Fluctuations of Wages and Unemployment. Manuscript, Univ. Pompeu Fabra. 
Rogerson, R., Shimer, R., Wright, R., 2005. Search-Theoretic Models of the Labor Market: A Survey. Journal of Economic Literature 43 (4), 959-88.

Rudanko, L., 2006. Labor Market Dynamics under Long Term Wage Contracting and Incomplete Markets. Manuscript, Univ. of Chicago.

Scarpetta, S., 1996. Assessing the Role of Labour Market Policies and Institutional Settings on Unemployment: A Cross-Country Study. OECD Economic Study \# 26.

Shimer, R., 2004. The Consequences of Rigid Wages in Search Models. Journal of the European Economic Association (Papers and Proceedings) 2, 469-79.

Shimer, R., 2005. The Cyclical Behavior of Equilibrium Unemployment and Vacancies. American Economic Review 95 (1), 25-49.

Silva, J., Toledo, M., 2005. Labor Turnover Costs and the Behavior of Vacancies and Unemployment. Manuscript, Rochester Univ.

Solon, G., 1985. Work Incentive Effects of Taxing Unemployment Benefits, Econometrica, 53 (2), 295-306. 


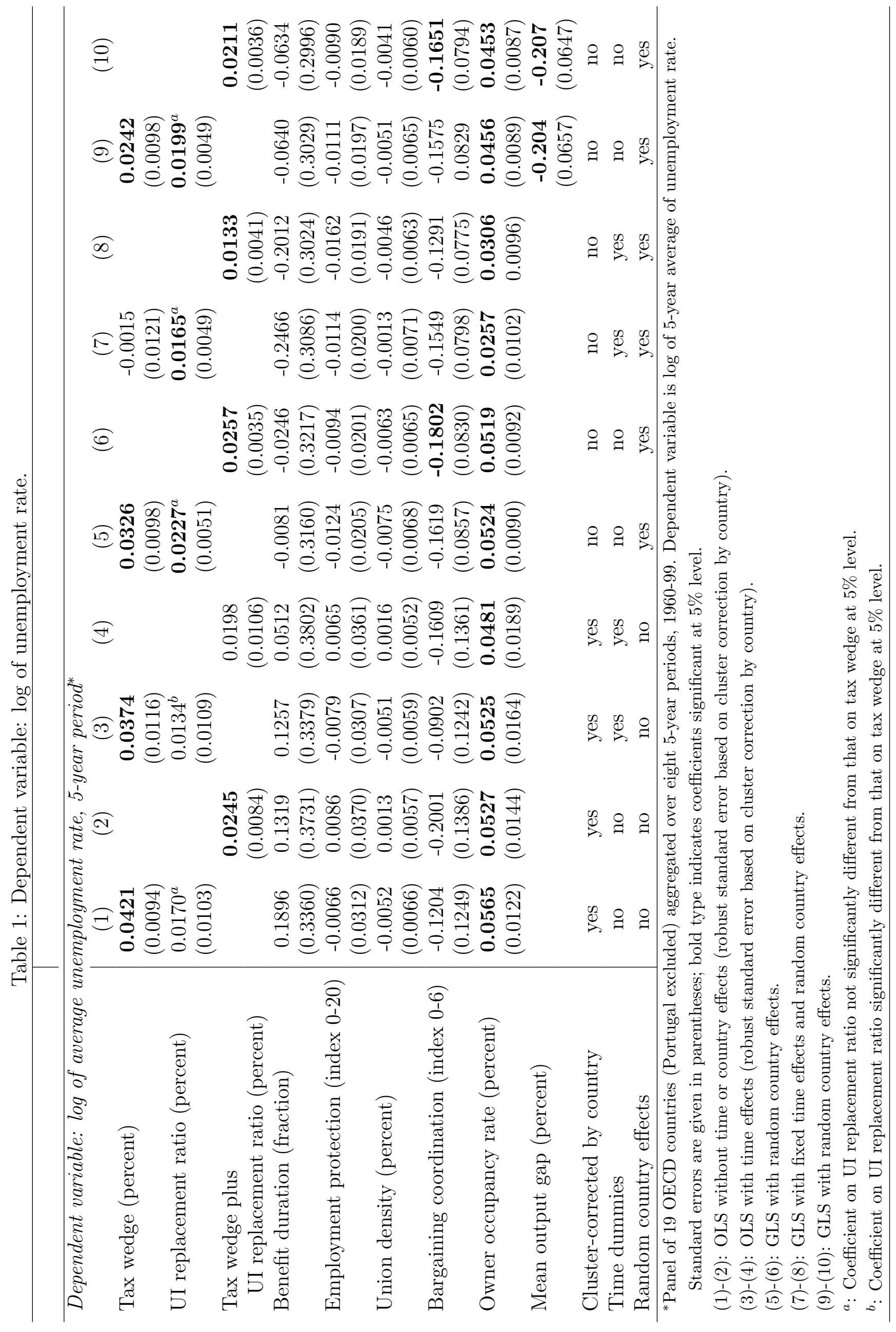




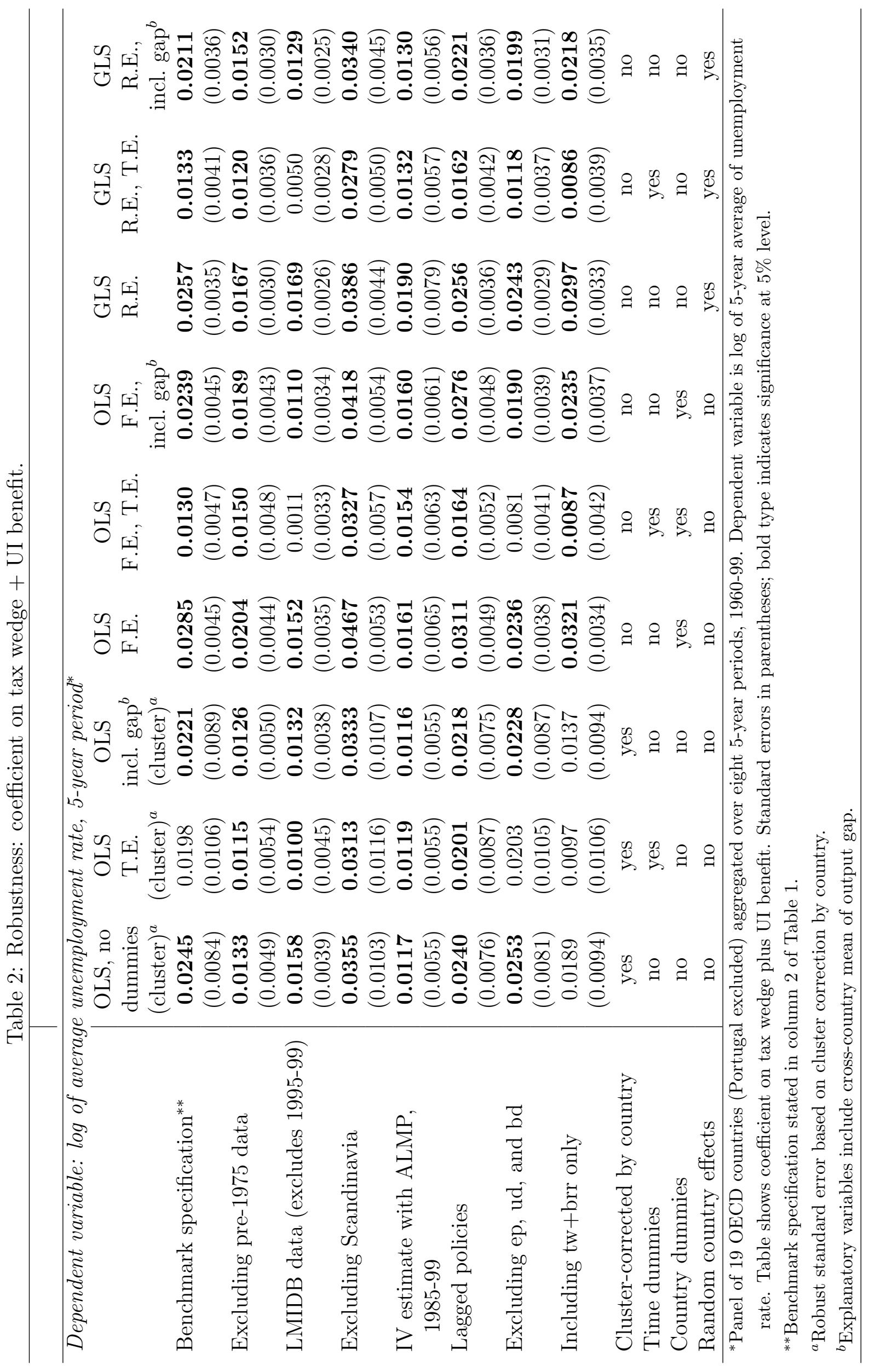




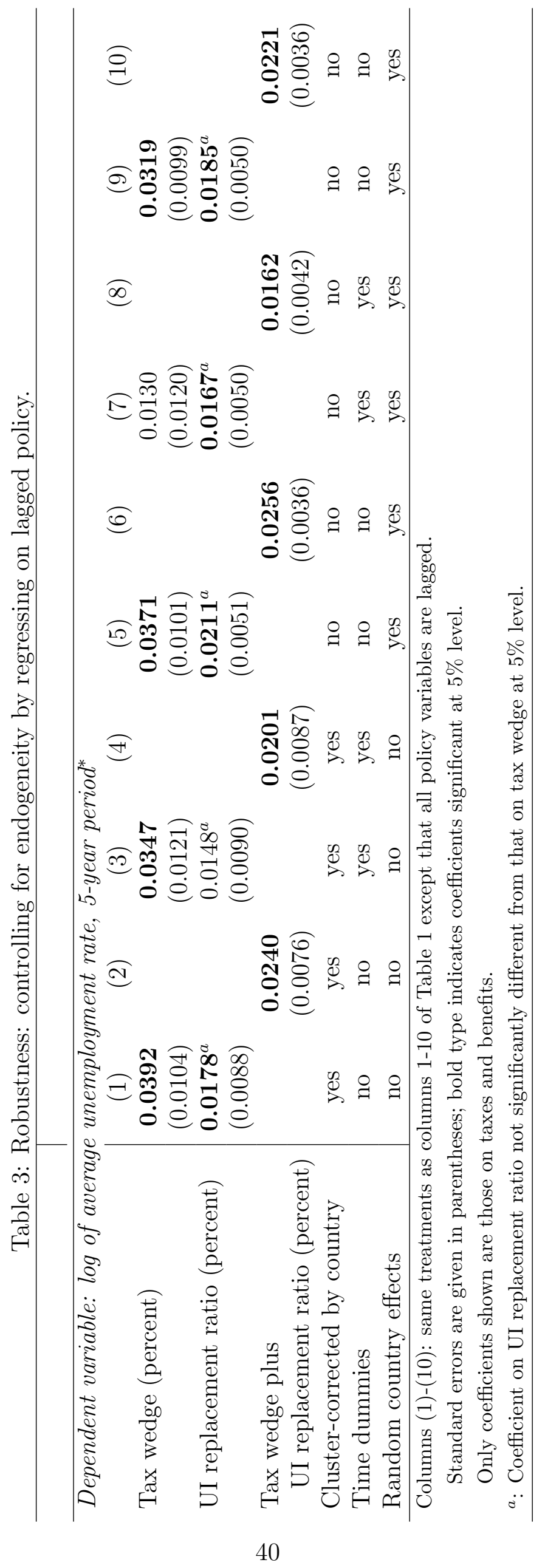




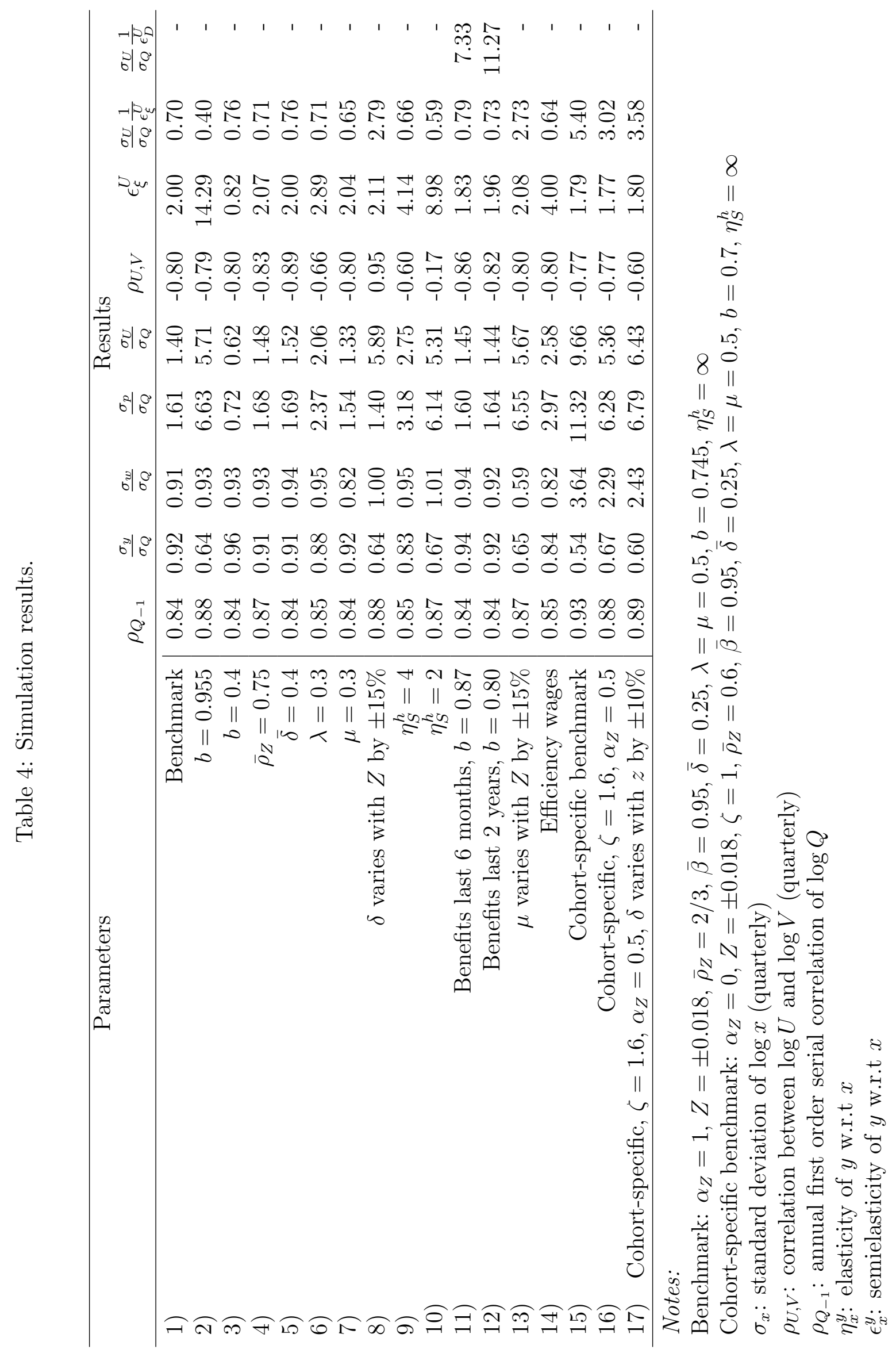

